\title{
COMPLIMENTS AND COMPLIMENT RESPONSES IN KUNMING CHINESE $^{1}$
}

\author{
Yi Yuan
}

\begin{abstract}
This article describes the way compliments and compliment responses are executed in Kunming Chinese, a Mandarin dialect spoken in Kunming, China. By looking at data collected through DCT questionnaires and natural observations, the author examines the semantic formulas used in forming compliments and compliment responses and the syntactic patterns of compliments in the two types of data. It is found that explicit compliments are the most common form of complimenting in the dialect. Implicit compliments, on the other hand, are much rarer and tend to occur by themselves. Syntactically, over $90 \%$ of the compliments fall into one of 4 syntactic structures paid through the third person/impersonal or second person perspectives. In replying to a compliment, speakers of Kunming Chinese are found to be drifting away from the tradition of rejecting compliments outright. They are more willing to accept compliments now although often indirectly. A quarter of the time, in real life situations, they just smile away a compliment they receive. While the DCT data and natural data are similar in the use of a majority of the semantic formulas, some differences are also found between the two types of data. Some methodological and cross-cultural implications are discussed at the end of the article.
\end{abstract}

Key words: Kunming Chinese, descriptive study, compliment event, DCT data, natural data.

\section{Introduction}

In the field of empirical pragmatics research, a lot of attention has been given to the exploration of pragmatic norms of different speech acts in different languages. Some examples include refusals in Chinese (Chen, Ye, \& Zhang, 1995), apologies in American English (Edmundson, 1992) and New Zealand English (Holmes, 1990),

${ }^{1}$ This study was carried out under the supervision of professors B. Hartford, K. Bardovi-Harlig, P. Newman, S. Obeng, and M. Yan of Indiana University, Bloomington. My sincere thanks go to all of them. I am also grateful for the critical comments and suggestions of the anonymous reviewers. The remaining errors are all mine. 
requests in Chinese (Zhang, 1995), complaints in Nepali English (Hartford, 1994), and compliments and compliment responses in American English (Herbert, 1986; Manes \& Wolfson, 1980; Pomerantz, 1978), New Zealand English (Holmes, 1988a) and Polish (Jaworski, 1995). Such studies are valuable in that they broaden our understanding of the pragmatic norms of different cultures and provide evidence for cross cultural comparisons.

Compliments and compliment responses have attracted particular attention from researchers because they not only give insights into the rules of language use in a speech community, but also show the value system of individual speakers as well as the community (cf. Knapp et al., 1984; Manes, 1983; Wolfson, 1984).

The term compliment has been defined in literature as "a speech act which explicitly or implicitly attributes credit to someone other than the speaker, usually the person addressed, for some 'good' (possession, characteristic, skill, etc.) which is positively valued by the speaker and the hearer" (Holmes, 1988a: 485). The ethnolinguistic term the author used to describe compliment activities to the informants in the field was '赞美' (literally 'beautify'), which is equivalent to what is treated as a compliment in English-speaking cultures as The New English-Chinese Dictionary (1979) translates the English word 'compliment' into '赞美' (literally 'beautify') and '夸 奖' (literally 'praise') in Chinese. The working definition of a compliment for this article will be an utterance that contains at least one explicit positive semantic carrier to give a positive evaluation to something that is related to the addressee. (1) below is an example of compliment in Kunming Chinese where the object - 'this house of yours' is complimented through the use of the explicit positive adjective 'beautiful':

$$
\begin{aligned}
& \text { 喔, 你 们这个房子 漂亮 了 } \\
& \text { (Particle) you (pl.) this house beautiful (Tense Marker) } \\
& \text { 'Wow, (Particle) } \\
& \text { 'Wow, this house of yours is beautiful (Particle).' }
\end{aligned}
$$

In cases where no positive semantic carrier is used, an utterance can only be regarded as a compliment if the complimentary force can be induced from the utterance itself in a situation where something good or positive is obvious and a compliment is normally expected. In (2), for example, 'you' notice that your friend is wearing a nice new dress and say to her:

$$
\begin{aligned}
& \text { 你 这条裙子哪里买的? 我也想买一条穿穿。 } \\
& \text { you this dress where buy I also want buy one wear } \\
& \text { 'Where did you buy your dress? I want to buy one myself.' }
\end{aligned}
$$

Here 'I want to buy one myself' is coded as an Implicit Compliment as it implies that the speaker likes the dress since people only buy things they think are good.

Serious research on the speech act of compliments began with a series of work by Wolfson and Manes on compliments in American English (Manes, 1983; Manes \& Wolfson, 1980; Wolfson, 1981, 1983, 1984; and Wolfson \& Manes, 1980). Based on almost 700 naturally occurring compliments by middle class Americans, Manes and Wolfson (1980) found for the first time that this speech act was highly formulaic in 
American English at the syntactic, semantic, and lexical levels. This formulaicness was later found to be true in other varieties of English and other languages, such as in New Zealand English (Holmes, 1988a), Hawaiian Creole English (Lee, 1990), Japanese (Daikuhara, 1986), Polish (Herbert, 1991; Lewandowska-Tomaszczyk, 1989), and Chinese (Ye, 1995).

Apart from the formulaicness of compliments found across cultures, some differences have also emerged. Herbert (1991), for instance, found that while compliments in English had a rather even distribution of first, second, and third person/impersonal focus, compliments in Polish had a predominant second person focus. The topic of compliments also varies. That is, American English speakers (Manes, 1983) and New Zealand English speakers (Holmes, 1988a) tend to compliment people on personal appearance, Polish speakers on the topic of possession (Herbert, 1991), Egyptian speakers on personality (Nelson, Bakary \& Al-Batal, 1993), and Chinese speakers on performance (Ye, 1995).

Compliments have also been studied in relation to such social factors as gender, age, and social distance. Wolfson (1989), for instance, found that more and lengthier compliments were given between acquaintances of equal status than between total strangers or intimates. This 'bulge' distribution of compliments was also found in Australian English (cf. Cordella, Large, \& Pardo, 1995). Women have been found to give and receive more compliments than men do, especially on their appearance, in American English, New Zealand English, and Hawaiian Creole English (Holmes, 1988b; Lee, 1990; Wolfson, 1983, 1984). Compliments also occur more often between interlocutors of the same gender, especially in female $\sim$ female interactions in American English (Knapp et al., 1984), New Zealand English (Holmes, 1988b), and Chinese (Ye, 1995). In addition, women tend to use more personal references (both first and second persons) and more intensifiers (Johnson \& Roen, 1992) than men do to express deference (cf. Herbert, 1990; Johnson \& Roen, 1992).

Most recent research on the speech act of compliment responses is based on Pomerantz' 1978 study. In general, cultures differ in terms of the extent to which they accept or reject a compliment. For example, although the Americans, the British, and the South Africans are all English-speaking, the latter two have been found to accept compliments more readily (about $2 / 3$ of the time) than the former (about $1 / 3$ of the time) (c.f. Herbert, 1986; Herbert \& Straight, 1989). Other cultures, such as the Japanese, the Chinese, and the French, tend to reject compliments more often (Chen, 1993; Daikuhara, 1986; Wieland, 1995).

In spite of the vast body of literature, compliments and compliment responses in Chinese have been studied less. The two major studies to date are Chen (1993) and Ye (1995). In Ye (1995), the author designed a Discourse Completion Task (DCT) questionnaire, collected 768 compliments from 96 informants and examined the linguistic forms of compliments and compliment responses, their relations to context and gender, and their functions. Out of the 768 compliments, only slightly over half were explicit compliments. The other half consisted of implicit compliments, opt outs, and non-complimentary remarks. In contrast to American English, which has a high frequency of compliments on interlocutors' appearance (Manes \& Wolfson, 1980), performance was the preferred topic of compliments in Mandarin Chinese. Regarding 
the relationship between the form of a compliment and the topic of a compliment, $\mathrm{Ye}$ found that while new sneakers elicited a very high percentage of no responses, the scenario of painting received the biggest number of explicit compliments, indicating that informants interpreted different scenarios differently. At the syntactic level, one characteristic of Chinese compliments was the high frequency of adjectives/stative verbs $(54.5 \%)$ and low frequency of verbs $(2.3 \%)$. This forms a sharp contrast with American English, which makes use of verbs to a greater extent $(16 \%$, Manes \& Wolfson, 1980).

Chen (1993) explores different politeness strategies used by Chinese and Americans in responding to compliments. She finds that the culturally valued Modesty Maxim leads the Chinese to denigrate themselves and elevate others by rejecting compliments they receive while the Agreement Maxim prevails over other considerations when Americans respond to compliments.

While these studies provide some insights into compliments and compliment responses in Mandarin Chinese, we have to bear in mind that the term 'Chinese' embraces numerous dialects and speech communities both within and outside China. Differences among these dialects and speech communities are bound to exist. We therefore need to look at different dialects or speech communities to gain a thorough understanding of the culture. In addition, the two studies on Chinese compliments, the Chen and Ye studies, not only used discourse completion task (or DCT) questionnaires alone to collect data, but the questionnaires were administered in China by someone other than the researchers themselves. Also, the subjects of the two studies were either university students or people with a tertiary educational level or above. As a result, the data used may not be readily generalisable.

The present study was designed to provide a comprehensive description of the compliment event in Kunming Chinese and to discuss some methodological issues. It aims to address the following research questions:

1. How do speakers of Kunming Chinese compliment? What are their compliments like in general?

2. How do speakers of Kunming Chinese respond to compliments?

3. Is the DCT a valuable and reliable data-gathering method as natural data? Are natural data as desirable as people think?

The speech community of Kunming and its dialect are worth studying because like many cities in China, Kunming is medium-sized and has become increasingly open to the outside world. By studying one speech community, we can come to an understanding of most cities in China. A general description of compliments in this dialect will provide an interesting perspective to look at Chinese pragmatics and will provide good bases for meaningful dialectal comparisons.

The research site of Kunming is the capital city of Yunnan province, China. The province borders with Tibet to the northwest, Burma to the west, and Laos and Vietnam to the south. It has a population of about $3 \frac{1 / 2}{2}$ million.

Kunming Chinese is one of the representative varieties of the South-western Mandarin spoken in the three mid- and south-western provinces of Sichuan, Yunnan, 
and Guizhou, as well as in parts of Hubei, Hunnan, Guangxi, Shanxi, and Gansu. The relationship between Kunming Chinese and the other dialects of China is shown in Figure 1 (adapted from Gui, 1990: 118).

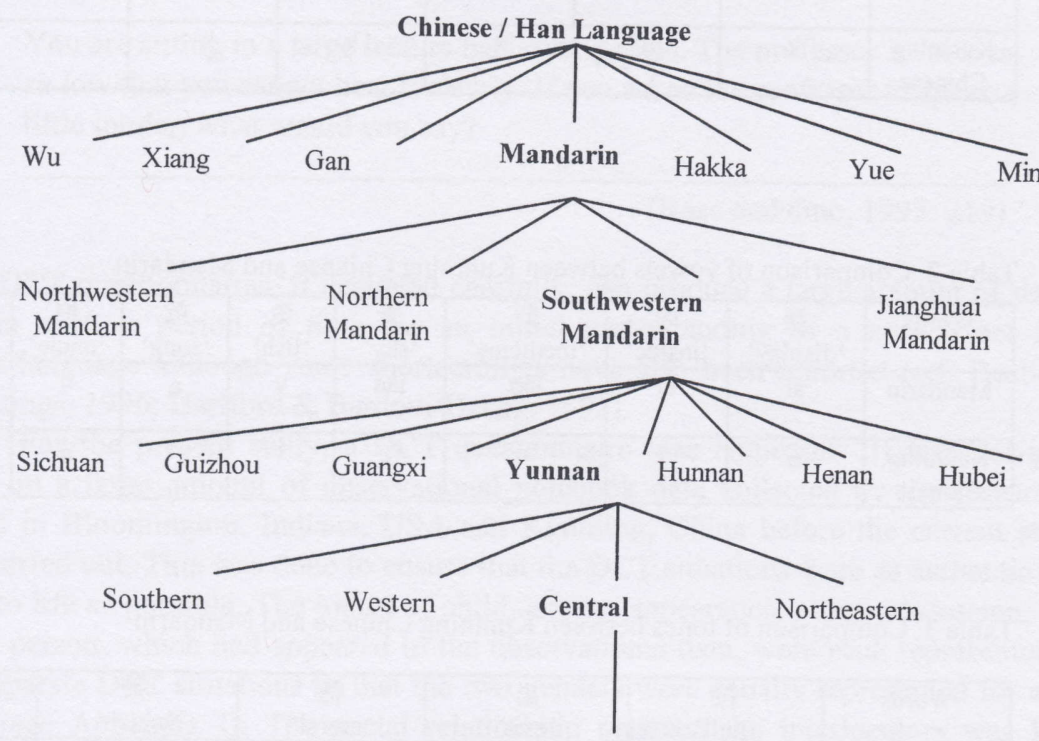

.....Kunming Chinese ......

Figure 1. The relationship between Kunming Chinese and the Chinese language

The differences between Kunming Chinese and the Northern Mandarin (or Mandarin in short, with Beijing dialect as the representative) mainly lie in the tones of words, the tone values of the tones, the lexicon, and the different pronunciations of some words. The following are some comparisons between Kunming Chinese and Mandarin adapted from Chan, 1981: 99-108. ${ }^{2}$

${ }^{2}$ The pronunciations of observational and interview data as well as oral DCT data used in the text are transcribed as they are spoken in Kunming Chinese with the following IPA symbols (Adapted from Norman, 1988: 192):

\begin{tabular}{lcccccc}
\hline \hline & Labials & $\begin{array}{c}\text { Plain } \\
\text { apicals }\end{array}$ & $\begin{array}{c}\text { Apical } \\
\text { Sibilants }\end{array}$ & $\begin{array}{c}\text { Retroflexe } \\
\mathrm{s}\end{array}$ & Palatals & Velars \\
\hline Voiceless unaspirated & $\mathrm{p}$ & $\mathrm{t}$ & $\mathrm{ts}$ & $\mathrm{ts}$ & $\mathrm{t} 6$ & $\mathrm{k}$ \\
Voiceless aspirated & $\mathrm{p}^{\mathrm{c}}$ & $\mathrm{t}^{\mathrm{c}}$ & $\mathrm{ts}^{\mathrm{c}}$ & $\mathrm{ts}$ & $\mathrm{t}^{\mathrm{c}}$ & $\mathrm{k}^{\mathrm{c}}$ \\
Nasals & $\mathrm{m}$ & $\mathrm{n}$ & & & & $(\mathrm{n})$ \\
Fricatives & $\mathrm{f}$ & & $\mathrm{s}$ & $\mathrm{s}$ & 6 & $\mathrm{x}$ \\
Sonorants & $\mathrm{w})$ & $\mathrm{l}$ & & $\mathrm{I}$ & $\mathrm{(j)}$ & \\
\hline \hline
\end{tabular}


Table 1. Comparison of initial consonants between Kunming Chinese and Mandarin

\begin{tabular}{|c|c|c|c|c|c|c|c|}
\hline Words & $\begin{array}{c}\text { 解 } \\
\text { to free' }\end{array}$ & $\begin{array}{c}\text { 齐 } \\
\text { 'together' }\end{array}$ & $\begin{array}{c}\text { 鞋 } \\
\text { 'shoe' }\end{array}$ & $\begin{array}{c}\text { 该 } \\
\text { 'should' }\end{array}$ & $\begin{array}{c}\text { 开 } \\
\text { 'open' }\end{array}$ & $\begin{array}{c}\text { 海 } \\
\text { 'sea' }\end{array}$ & $\begin{array}{c}\text { 业 } \\
\text { 'career' }\end{array}$ \\
\hline Mandarin & $\mathrm{t} 6$ & $\mathrm{t} 6^{6}$ & 6 & $\mathrm{k}$ & $\mathrm{k}^{6}$ & $\mathrm{x}$ & $\varnothing$ \\
\hline $\begin{array}{c}\text { Kunming } \\
\text { Chinese }\end{array}$ & $\mathrm{k}$ & $\mathrm{t} 6^{6}$ & $\mathrm{x}$ & $\mathrm{k}$ & $\mathrm{k}^{6}$ & $\mathrm{x}$ & $\mathrm{n}$ \\
\hline
\end{tabular}

Table 2. Comparison of vowels between Kunming Chinese and Mandarin

\begin{tabular}{|c|c|c|c|c|c|c|c|c|c|}
\hline Words & $\begin{array}{c}\text { 摆 } \\
\text { 'display' }\end{array}$ & $\begin{array}{c}\text { 内 } \\
\text { 'inside' }\end{array}$ & $\begin{array}{c}\text { 药 } \\
\text { 'medicine' }\end{array}$ & $\begin{array}{c}\text { 天 } \\
\text { 'sky' }\end{array}$ & $\begin{array}{c}\text { 鱼 } \\
\text { 'fish' }\end{array}$ & $\begin{array}{c}\text { 歌 } \\
\text { 'song' }\end{array}$ & $\begin{array}{c}\text { 伯 } \\
\text { 'uncle' }\end{array}$ & $\begin{array}{c}\text { 却 } \\
\text { 'but' }\end{array}$ & $\begin{array}{c}\text { 缺 } \\
\text { 'lack' }\end{array}$ \\
\hline Mandarin & ai & ei & iao & ian & y & ə & o & ye & ye \\
\hline $\begin{array}{c}\text { Kunming } \\
\text { Chinese }\end{array}$ & $\varepsilon$ & ue & io & i $\varepsilon$ & i & 0 & ə & io & ie \\
\hline
\end{tabular}

Table 3. Comparison of tones between Kunming Chinese and Mandarin

\begin{tabular}{|c|c|c|c|c|c|}
\hline Words & $\begin{array}{c}\text { 拉 } \\
\text { 'pull' }\end{array}$ & $\begin{array}{l}\text { 出 } \\
\text { 'exit' }\end{array}$ & $\begin{array}{c}\text { 德 } \\
\text { 'moral' }\end{array}$ & $\begin{array}{c}\text { 哪 } \\
\text { 'which' }\end{array}$ & $\begin{array}{c}\text { 布 } \\
\text { 'cloth' }\end{array}$ \\
\hline Mandarin & Level (1) & Level (1) & Rise (2) & Fall-Rise (3) & Fall (4) \\
\hline $\begin{array}{l}\text { Kunming } \\
\text { Chinese }\end{array}$ & Level (1) & Rise (2) & Rise (2) & Fall (4) & Fall-Rise (3) \\
\hline
\end{tabular}

All data analysed in this study were collected by the researcher in Kunming during the months of December 1996 to April 1997.

\section{Methodology}

\subsection{The data}

Three types of data were collected. These are DCT data, natural observational notebook data, and recorded interview data.

The tone of a character is indicated by a number (from 1-4) after the sound notation. Number 1 stands for the first or the level tone, 2 for the rising tone, 3 for the fall-rise or contour tone, and 4 for the falling tone. A sound notation without a number means the character is unstressed. 
The DCT is a written questionnaire that contains a number of hypothetical scenarios or situations used to elicit a certain speech act. Respondents are required to supply, in writing, what they would say in real life if similar situations happen to them. An example is given in (3) below.

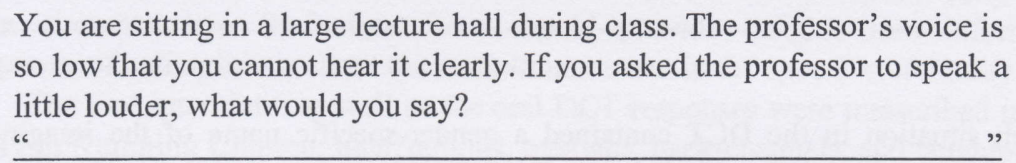

(Rose and Ono, 1995: 219)

Such DCT questionnaires, if designed carefully, can produce a large amount of useful data in a short period of time for an initial understanding of a speech act in a dialect/language although some shortcomings have also been reported (c.f. Beebe \& Cummings, 1996; Hartford \& Bardovi-Harlig, 1992).

For the present study, a DCT questionnaire (see Appendix II) was designed based on a large amount of observational notebook data collected by the researcher herself in Bloomington, Indiana, USA and Kunming, China before the current study was carried out. This was done to ensure that the DCT situations were as authentic and close to life as possible. The topics of child, ability, appearance, attire, possession, and whole person, which had appeared in the observational data, were each represented in two separate DCT situations so that the two genders were equally represented for each topic (see Appendix I). The social relationship between the interlocutors was kept constant at the equal status level between acquaintances, neighbours, colleagues, or friends. The questionnaire had been tested twice among native speakers of Kunming Chinese and had been revised according to their feedback before it was administered in Kunming, China.

The questionnaire had two parts. Part I consisted of 12 situations where the informant was said to have noticed something explicitly positive or nice about the DCT interactant and was expected to pay a compliment to the interactant in a normal situation. So in (4), a compliment is expected because 'your' acquaintance has achieved so much academically and because of the given sentence "you said to her with admiration".

\begin{abstract}
熟人朱雁不到三十岁就拿到北大的博士学位, 还找到一个很 好的工作. 昨天你磁到她, 说起这事, 感慨地对她说: (Zhu Yan, an acquaintance, got her Ph.D. from Beijing University before she turned thirty and then found a very good job. When you saw her yesterday, you talked about it. You said to her with admiration:)
\end{abstract}

Part II of the DCT had 12 dialogue-type situations with compliments to see how informants would respond to these compliments: 


\begin{abstract}
天朋友丽丽到你家玩, 一进门就说: “你家揙得这么好, 又干净” 你对她说:

(You always keep your house clean and tidy. One day your friend Li Li dropped by and was very much impressed. She said, "Your place is always so nice and clean!" You said to her:
\end{abstract}

Each situation in the DCT contained a gender-specific name of the imagined DCT interlocutor, the relationship between the DCT interlocutor and the respondent, and the scenario that calls for a compliment or a response to a compliment. No third parties were involved in the scenarios except for situations 1 and 3, where the third party was a child who was also the prospective object of compliment directed to the parent. Respondents were given an opportunity to opt out if they thought they would not say anything in a given situation.

The DCT was administered in two ways, i.e., orally and in writing, to reduce such undesirable effects of written DCTs as producing data that are more direct and less hedged (Beebe \& Cummings, 1996; Hartford \& Bardovi-Harlig, 1992) and that contain fewer features of oral speech (Yuan, 2001) than oral data. A combination of the two forms of the DCT may cancel out these effects and provide a truer picture of the compliment pragmatics of Kunming Chinese.

\title{
2.2. The subjects and the data-collection procedure
}

Altogether, 175 informants (90 males and 85 females) responded to the DCT questionnaire. The informants were selected by the method of judgement sampling. In particular, Milroy's (1980) methodological framework of social network was used to establish initial contacts, through whom more informants were identified and contacted until the desired number of informants from different age, gender, and educational groups were recruited. The three age groups (18-29, 30-49, 50 years old or older), three educational levels (the junior high school or below group, the high school group, and tertiary and above group), as well as the two gender groups were about equally represented in the oral, written, and interview subject pools so that the data could represent the whole population rather than a certain sector of it. Because the two genders were equally represented in the DCT situations and about equally represented in the subject pool, there should be no gender bias in the data collected. A detailed analysis of the correlation between gender (as well as other social factors) and the use of compliments is reported in a separate work (c.f. Yuan, 2000).

The written DCT questionnaire was filled out by 88 ( 46 males and 42 females) of the 175 informants at their own pace and in a place of their own choice. Another 87 informants (44 males and 43 females) responded to the DCT orally. The oral DCT was done in the following way. First, the DCT situations were tape-recorded by two (one male and one female) native speakers of Kunming Chinese in their $30 \mathrm{~s}$ in a neutral tone and intonation. Informants were then invited to the researcher's residence individually at a time of their choice. They listened to one situation at a time and responded to the 
situation orally before the next situation was played to them. A second tape-recorder recorded the oral sessions in their entirety. Interviews were conducted and audio-taped with 51 ( 24 males and 27 females) of the 87 oral DCT informants right after their oral DCT sessions to find out whether and why they thought they complimented people and whether there was anybody they would not feel comfortable complimenting under certain circumstances. Such interviews should provide insights into informants' perceptions of and opinions about the compliment event in the speech community.

The oral interviews as well as the oral DCT responses were transcribed in their entirety in Kunming Chinese. Interruptions, overlaps, back-channels, and laughter were noted, but no effort was made to time pauses or other temporal cues.

A data pool of 256 occurrences of compliments were also penned down in notebooks by the researcher at the research site of Kunming during the 4 months of her field work. She wrote down, either right after a compliment exchange or at the end of the day, all the compliments that occurred around her, with or without her participation. These included compliment exchanges that occurred in the street, on the bus, in hospital waiting rooms, at class reunions, in friends' homes, or at work places or dinner tables. Relevant contextual information and interlocutors' relationship to each other as well as their age and gender were recorded in the notebook whenever such information was available. Table 4 presents a rough profile of the participants of the 256 compliment events. The high proportion of females and participants in the $30-45$ age group in this data pool may reflect a bias resulted from the researcher's own personal profile and social circle.

Table 4. Profile of participants of the observational data

\begin{tabular}{lllll}
\hline Age & $>20$ years & $30-45$ & $<50$ years & Total \\
Complimenter & 1 & 198 & 57 & 256 \\
Complimentees & 5 & 174 & 77 & 256 \\
\hline Gender & Females & & Males & Total \\
Complimenters & 198 & & 58 & 256 \\
Complimentees & 195 & & 61 & 256 \\
\hline
\end{tabular}

The purpose of collecting the three different types of data was to give a full and complementary picture of the compliment pragmatics in Kunming Chinese, as each form of the data may provide different perspectives on the same subject of compliment in terms of linguistic forms and theoretical/methodological implications (see Yuan, 2001). Results of the DCT questionnaire (oral and written data combined) and the observational notebook data will be reported both quantitatively and qualitatively and interview data will be used as supporting evidence when appropriate.

\subsection{Data-coding}


The compliment event in Kunming Chinese will be described in terms of the semantic formulas used and the syntactic structures of the compliments. The term 'semantic formula' is defined as those parts of a reply/utterance that "represent the means by which a particular speech act is accomplished in terms of the primary content of an utterance, such as a reason, an explanation, or an alternative" (Hartford \& BardoviHarlig, 1992: 34). The following semantic formulas are used to categorise compliments and compliment responses in the data pool:

\section{Compliments}

Unbound Semantic Formulas

Explicit Compliment

Implicit Compliment

Bound Semantic formulas

Explanation

Information Question

Future Reference

Contrast

Advice

Request

Non-Complimentary Replies

Non-Compliment

Opt Out

\section{Compliment Responses}

Acceptance

Explanation

Return

Appreciation

Upgrade

Reassignment

Suggestion

Invitation

Confirmation Question

Downgrade

Disagreement

\section{Opt Out}

The semantic formulas for compliments are divided into 2 macro categories, namely Compliments and Non-complimentary Replies. Compliments are further divided into Unbound and Bound semantic formulas. The unbound semantic formulas refer to Explicit Compliments (with at least one positive semantic carrier) and Implicit Compliments, both of which can be interpreted as compliments of one kind or another by their surface forms. So 'Nice dress' is an Explicit Compliment because of the positive semantic carrier 'nice'. An Implicit Compliment is often a general statement with or without a positive semantic carrier, where the addressee is not directly mentioned but the positive meaning can be inferred from what is said in a particular context. So when someone says upon noticing her friend wearing a nice new dress 'Where did you buy this dress? I want to buy one myself', the part 'I want to buy it myself' is coded as an Implicit Compliment as it implies that the speaker likes the dress since people only buy things they think are good.

The bound semantic formulas are things that have to co-occur with one of the unbound semantic formulas to be interpreted as part of a compliment. So the question 'Where did you buy this dress?' is not coded as a compliment if it occurs by itself as we cannot make any positive inference from the question itself without any context or without the presence of a positive semantic carrier. However, if I say 'Nice dress. Where did you buy it?', then the question is coded as a token of Information Question because of the Explicit Compliment 'Nice dress'. 
Non-complimentary Replies include Non-Compliments and Opt Outs. NonCompliments are either bound semantic formulas occurring by themselves or other replies that do not carry any positive meanings whereas Opt Outs are cases where informants do not say/supply anything in a situation where a compliment is usually expected. (6) below provides examples of each of the semantic formulas.

\section{(6). Explicit Compliment}

你儿子太乘了。

you(r) son so good/obedient (Tense Marker)

'This child of yours is extremely good.'

\section{Implicit Compliment}

只要人好看, 无论任何发型都是好看的.

as long as man good looking no matter any hairstyle all be good looking

'As long as (one's) good looking, any hair style would look good.'

\section{Explanation}

1 喔, 漂亮了, 一个家再 反这份, 再反这份配上

(Particle) beautiful a home again like this again like this coupled with

that blue colour carpet so comfortable (Tense Marker) one place too

不想去了, 一天就想在家首.

not want go (Tense Marker) one day only want be home in

'Wow, (it's) beautiful. A house with a, with a blue carpet like this (is) so comfortable. (You) don't want to go anywhere, but only want to stay home.'

\section{Information Question}

嗼呀, 这个地毯太好看了. 你在哪点买的?

(Particle) this carpet so good looking you be where buy

'Gosh, this carpet is so pretty. Where did you buy it?'

\section{Future Reference}

蛮能干了嘛! 二天当 个博士没得问题。

quite capable (Particle) future become one $\mathrm{PhD}$ no problem

'Quite capable (Particle)! There shouldn't be any problem (for you) to get a Ph.D. in the future.'

\section{Contrast}

你家这个太乘了嘛, your home this one so

不

腄觉, 喊她做点事讨价还价的, 点都不听话 not sleep call her do little thing bargain little not listen words 'This child of yours is so good (Particle), not at all like mine, (who) doesn't come home until midnight. When (I) ask her to do something, (she) bargains. (She's) not obedient at all.' 
1 你这个房子装修得好, 钱花得值得! 有了钱呢 your this house renovate good money spent worthy have money (Particle)

2 就是要 享受。钱 嘛是死的, 你摆都起嘛还 should want enjoy money (Particle) is dead you put away (Particle) still

3 不是摆都, 拿了就要 花。 not be put away take (Tense Marker) should spend

'This house of yours is very well renovated. The money was well spent. (One) should enjoy (life) when one has money. Money (Particle) is lifeless. (It) doesn't change if you just let it sit there (Particle). (We) should spend (it) when we have (it).

\section{Request}

你的这件衣裳 好瞧, 借 我穿两日嘛. your this clothes good looking lend me wear two days (Particle) 'This dress of yours is good looking. Lend it to me and let me wear it for a couple of days (Particle).'

\section{Non-Compliment}

咋个你个憼一日就是为别人, 还是应该想想自己呢 how you one stupid one day be for others still be should think self (Particle) 'Why are you so stupid, thinking about others all the time! (You) should think about yourself (Particle).'

\section{Opt Out No response}

Compliment responses are defined as anything that follows a compliment, verbal or non-verbal. Based on previous studies on compliment responses (mainly Chen, 1993; Herbert, 1990; Holmes, 1988a; and Pomerantz, 1978), 12 semantic formulas have been identified to categorise the data. The first 9 are acceptances of some kind while Downgrade and Disagreement are rejections . (7) are examples for each of the 12 semantic formulas.

(7). 1. Acceptance (Replying to a compliment on new dress at wedding)

我很高兴你也这样说。

I very glad you too like this say

'I'm very glad you said so too.'

2. Explanation (Replying to a compliment on a new colour TV)

这电视画面大, 看起来舒服, 感觉 好.

this TV screen big see rise comfortable feel good

'This TV has a big screen, which makes TV-watching comfortable and enjoyable.'

3. Return (Replying to a compliment on a clean, nice house)

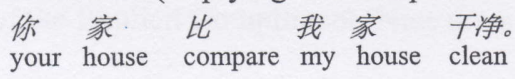


'Your house is cleaner than mine.'

4. Appreciation (Replying to a compliment on a nice outfit)

咯是? 感谢.

(Particle) be thanks

'Is it? Thanks.'

5. Upgrade (Replying to a compliment on a nice outfit)

我平时候比这个还漂亮。

I normally compare this more beautiful

'I look even more beautiful at other times.'

6. Reassignment (Replying to a compliment on a chess champion) 都是老师教得好。

all be teacher teach good

'It's all because the teacher/coach did a great job.'

7. Suggestion (Replying to a compliment on a new colour TV)

你去买 一台 嘛

you go buy one set (Particle)

'Go and buy one yourself (Particle).'

8. Invitation (Replying to a compliment on kindness)

叫大力 经常来 玩。

ask $\mathrm{Da} \mathrm{Li}$ often come play

'Ask Da Li to come and play often.'

9. Confirmation Question (Replying to a compliment on looking)

咯

是?

(Particle) be

'Is it?'

10. Downgrade (Replying to a compliment on generosity)

朋友之间帮点忙, 算不了什么

friend between help little busy count not what

'It's just friends helping each other out. Nothing worth mentioning.'

11. Disagreement (Replying to a compliment on a clean, nice house)

干净 哪样

clean what

'Not clean at all!'

12. Opt Out (No reply or just a smile) 


\section{Results and Discussion}

In the following, results of the DCT data (oral and written combined) and the natural data will be presented quantitatively ${ }^{3}$ in separate sections. Findings will be analysed locally where appropriate.

\subsection{Compliments}

\subsubsection{An overall view of compliments in the DCT data}

There are altogether 2100 replies collected from the 12 compliment scenarios by the 87 oral and 88 written DCT respondents $[(12 \times 87)+(12 \times 88)=2100]$. These replies produce 2979 tokens of semantic formulas as some responses contain combinations of two or more semantic formulas.

Table 5. An overall view of the DCT responses: Compliments

\begin{tabular}{|c|c|c|c|}
\hline & & Raw Numbers & $(\%)$ \\
\hline \multirow{2}{*}{ Compliments } & Explicit Compliments & 1745 & $(83.10)$ \\
\cline { 2 - 4 } & Implicit Compliments & 120 & $(5.71)$ \\
\hline \multirow{2}{*}{$\begin{array}{c}\text { Non-complimentary } \\
\text { Replies }\end{array}$} & Non-Compliments & 163 & $(7.76)$ \\
\cline { 2 - 4 } & Opt Outs & 72 & $(3.43)$ \\
\hline Total & 2100 & 100 \\
\hline
\end{tabular}

As shown in Table 5, among the 2100 replies, 1745 or $83.1 \%$ are Explicit Compliments, indicating that people prefer to issue a clear positive statement when they pay compliments. Another 120 replies (or 5.71\%) are Implicit Compliments that also belong to the big category of Compliments. This means that people compliment in almost $90 \%$ of the complimenting situations ${ }^{4}$ created in the DCT.

However, the fact that Non-Complimentary Replies have a relatively high frequency $(7.76 \%$ Non-Compliments $+3.43 \%$ Opt Outs $=11.19 \%)$ shows that not everybody compliments in a situation where a compliment is called for. In example (8), respondent 16 expresses his non- disappointment in seeing the newly-cut hair style of his imagined DCT friend even though "she looks very energetic and cute":

[Scenario 7, new hair cut]

长头发为哪样不留着?

ts' $\varepsilon 2$ t’ou2 fa2 wei3 na4 je3 pu2 liu2 tşo2

${ }^{3}$ The two forms of the DCT as well as the notebook and interview data produced some differences in terms of linguistic forms as well as the length and number of turns of interactions. For a more detailed discussion, please see Yuan, 2001.

${ }^{4} \mathrm{~A}$ complimenting situation is a situation where something positive or nice is obvious and a compliment is usually expected. As the DCT scenarios were all based on authentic observational data where compliments had actually occurred in similar real life situations, they are all regarded as complimenting situations. 
long hair why not keep

'Why (didn't you) keep (your) long hair?'

(Oral DCT) [Non-Compliment] (16-M-Y-C) $)^{5}$

When asked whether he would compliment the interlocutor if he liked the new hair style of his friend, the same respondent said he still would not because he did not like women with short hair.

The other type of reply that does not belong to compliment is Opt Out, where a respondent decides not to say anything in a given situation. 72 of the 2100 responses belong to this category. This may be because some people do not feel comfortable complimenting people face-to-face. The following comment from my interview with an elderly, high-school educated female respondent may illustrate this point. (9) $\ldots \ldots$

1 像我们这些人的这个性格么就是对别人

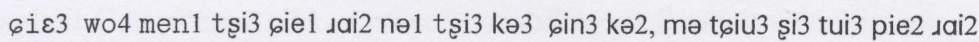
like we these people's this character be to other people

2 的称赞 嘛就是一笑了之, 觉得别人好也经

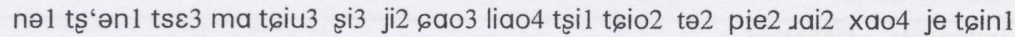
compliment (Particle) be smile away feel others good too often

3 常 想只在心里面想就算了, 也不去, 咯合,

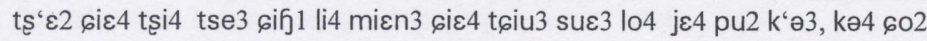
think only be heart inside think that's it either not go right

4 对别人的议论也一般不去附和, 就是这种了, tui3 pie2 ^ai2 nə ji3 luen3 je4 ji2 pe1 pu2 k'ə3 fu3 6o2, tciu3 și3 tşi3 tson4 lo to others' comments too generally not go along that be like this

5 就是自己有自己的生活原则, 嘎有生活原则,

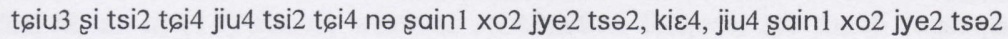
that be self have own life principle (Particle) have life principle

6 该讲的讲, 不该讲的不讲

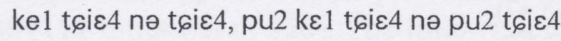
should say say not should say not say

'The character of people like us is to throw a smile to people's compliment (Particle). When (we) think somebody is good, (we) only ponder about it in (our) heart. (We) also do not (Particle) join in other people's comments. That is it. (We) have our own principles of life, right, principles of life. (We) say what we should say and refrain from what (we) shouldn't.'

(83-F-O-H)

${ }^{5}$ The number and letters in the brackets after each example represent the identification of the respondent who produced the example. Respondents are coded as Subject Number-Gender-AgeEducational Level. For age, $\mathrm{Y}$ stands for the younger group, $\mathrm{M}$ for the middle-aged group, $\mathrm{O}$ for the older group. For educational level, J stands for junior high school, $\mathrm{H}$ for high school, and $\mathrm{C}$ for college. So (110-M-Y-C) means subject number 110, male, young, college educated. 
In other words, even though sometimes someone may feel something positive about the interlocutor, he/she may still refrain from complimenting that person.

In the following, we will look at the compliments more closely. Table 6 summarises the overall distribution of the semantic formulas in the DCT data. We see that Explicit Compliments account for a majority of them $(58.58 \%)$. What is also interesting is that while Explicit Compliments may co-occur with bound semantic formulas or appear by themselves, a majority (92.5\%) of the Implicit Compliments occur by themselves. It seems then that the two types of compliments behave rather differently. The single Explicit Compliments in the data pool look like (10) below:

(10) [Scenario 7, new hair-cut]

$$
\begin{aligned}
& \text { 你 很 漂亮! } \\
& \text { you very beautiful } \\
& \text { You're very beautiful. (Written DCT) [Explicit Compliment] (110-M-Y-C) }
\end{aligned}
$$

Table 6. The overall distribution of semantic formulas in the DCT data: Compliments

\begin{tabular}{|lccc|}
\hline \hline Semantic Formulas & Raw Tokens (\%) & Singleton (\%)* & Combination (\%) \\
\hline Compliments - Unbound & $1745(58.58)$ & $879(50.37)$ & $866(49.63)$ \\
Explicit Compliment & $120(4.03)$ & $111(92.5)$ & $9(7.5)$ \\
Implicit Compliment & & & \\
Compliments - Bound & $384(12.89)$ & & $384(100.00)$ \\
Explanation & $184(6.18)$ & & $184(100.00)$ \\
Information Question & $116(3.89)$ & $116(100.00)$ \\
Future Reference & $106(3.56)$ & $61(100.00)$ \\
Contrast & $61(2.05)$ & $28(100.00)$ \\
Advice & $28(0.94)$ & & \\
Request & & & \\
Non-Complimentary Replies & $163(5.47)$ & & \\
Non-Compliments & $72(2.42)$ & \\
Opt Out & $2979(100)$ & \\
\hline Total & & \\
\hline \hline
\end{tabular}

* The total sum of singletons and combinations on each row should be the same as the number of raw tokens of the same row.

About half of the Explicit Compliments co-occur with one or more of the bound semantic formulas, such as in (11), although such combinations rarely exceed three semantic formulas.

(11) [Scenario 3, obedient child]

1 你家这个太乘了嘛哪个像我家的, 深更 ni4 tce 1 tşi3 kə3 t'e 2 kue1 lo ma na4 ko2 cie2 wo4 tçia1 nə sain1 kain1 your home this one so good (Particle) which one like mine deep night

2 半夜不睡觉喊她做点事讨价还价的, 
pe3 je3 pu2 sui3 t6ao3, xan4 t'a tsuo 3 tiə 4 si3 t'ao4 tsa3 xuع2 tsa3 nə midnight not sleep ask her do little thing bargain

点 都 不听 话.

tiə4 tou1 pu2 t'in 1 xua3

little all not listen words

'This child of yours is so good (Particle), not at all like mine, who doesn't come home until midnight. When (I) ask her to do things, (she) bargains. (She's) not obedient at all.'

(Oral DCT) [Explicit Compliment] [Contrast] (4-M-Y-J)

Explicit Compliments combine most frequently with Explanations: There are 384 (or nearly 13\%) occurrences of Explanations out of the total semantic formulas of 2979. Among these occurrences, only 6 co-occurred with Implicit Compliment whereas the rest are combinations with Explicit Compliment.

Information Question is another semantic formula that frequently co-occurs with Explicit Compliment. It can precede or follow an Explicit Compliment. A typical Information Question asks about where or when something is purchased:

[Scenario 9, new carpet]

茀呀, 这个地毯太好看了。你在哪点买的?

ai4 ja4 tsi3 kə ti3 t' $\varepsilon 4$ t'e 3 xao 4 k' $\varepsilon$ lo, ni4 tse 3 na4 tiə4 me4 nə

(Particle) this carpet so good looking you in where buy

'Gosh, this carpet is so pretty. Where did you buy it?'

(Oral DCT) [Explicit Compliment] [Information Question] (77-F-O-J)

The bound semantic formulas of Future Reference and Contrast have roughly the same frequency, but interestingly, Contrast co-occurs only with Explicit Compliment, as in (11) above, whereas Advice and Request are much less common compared with all the other semantic formulas.

Implicit Compliments, on the other hand, tend to occur by themselves most of the time (111 times out of 120). The following is an example:

[Scenario 7, new hair cut]

只要人好看, 无论任何发型都是好看的. as long as person good looking whatever hair style all be good looking 'As long as (one's) good looking, any hair style would look good.'

(Written DCT) [Implicit Compliment] (53-F-Y-H)

When an Implicit Compliment does combine with something else, it is found to cooccur mostly with Explanations (6 out of the 9 combination cases).

Finally, combinations of the unbound and bound semantic formulas occur in one turn at one stretch in the DCT data, as in (12), because of the non-interactive nature of DCTs although occasionally oral DCT respondents can be quite imaginative and may create an additional turn in their responses:

[Scenario 4, a capable person] 
一你修理这个计算是专业的呢还是业余学习的? you fix this computer be professional or be amateur learn

Do you fix computers professionally or do you do it at your spare time?

2 - (如果是业余的)

if be amateur

(If it's a spare time hobby, I'll say)

3 - 你很能干, 恩, 肯钻研。

you very capable (Particle) willing study

You're very capable, um, and willing to work hard.

$(42-\mathrm{M}-\mathrm{O}-\mathrm{C})$

In summary, we have seen that in the DCT situations, people often compliment overtly. Occasionally, however, they may make general references or noncomplimentary remarks, or they may even prefer not to say anything.

\subsubsection{An overall view of compliments in the natural observational data}

Table 7. An overall view of the natural observational data: Compliments

\begin{tabular}{|c|c|c|c|}
\hline & & Raw Numbers & $(\%)$ \\
\hline \multirow{2}{*}{ Compliments } & Explicit Compliments & 242 & $(94.53)$ \\
\cline { 2 - 4 } & Implicit Compliments & 14 & $(5.47)$ \\
\hline $\begin{array}{c}\text { Non- } \\
\text { complimentary } \\
\text { Replies }\end{array}$ & Non-Compliments & 0 & $(0)$ \\
\cline { 2 - 4 } & Opt Outs & 0 & $(0)$ \\
\hline Total & & 256 & 100 \\
\hline
\end{tabular}

In general, compliments recorded in the observational notebook data resemble what we have seen in the DCT data to a certain extent. Table 7 shows that while the percentage of Implicit Compliment remains roughly the same in the natural data as in the DCT data (a little over 5\%), the ratio of Explicit Compliment increases to almost 95\% from the $83.10 \%$ of the DCT. This increase results from the no show of Non-Complimentary Replies, including Non-Compliments as well as Opt Outs, understandably because the researcher only noted down utterances that fit her definition of 'compliments', i.e. utterances that contained at least one positive semantic carrier or utterances with an induceable positive meaning. This difference between the natural data and the DCT data highlights the possibility that natural observations may not capture cases where people prefer not to say anything about something positive or nice, a disadvantage that has not been recorded so far.

Table 8 shows that the 256 compliments that occurred in natural settings yield 390 semantic formulas. The percentages of Explicit Compliments $(62.05 \%)$ and Implicit Compliments (3.59\%) are similar to those of the DCT data $(58.58 \%$ \& $4.03 \%$, see Table 6), reinforcing our earlier observation that speakers of Kunming Chinese prefer explicit statements when they pay compliments. The other numerical similarity 
between the DCT data and the natural data is the percentage of Explanations (over $12 \%)$.

However, when we compare Table 8 with Table 6, some differences between the DCT data and the natural data also emerge: (i). All the Implicit Compliments occur by themselves in the natural data whereas $7.5 \%$ of them co-occur with one or more bound semantic formulas in the DCT data. (ii). The semantic formula of Contrast appears more frequently in real life than in the DCT situations (10\% vs. $3.56 \%)$ whereas Information Question is more common in DCT $(6.18 \%)$ than in real life $(3.59 \%)$. (iii). The bound semantic formulas of Advice and Request do not appear at all in the natural data; Future Reference only appears once in the natural data but it appears a few times in the DCT data. (iv). Finally, the natural data contain the use of Conversation Openers, Address Terms, and Appreciation Tokens that do not exist at all in the DCT data. These are exemplified in (15) to (17).

Table 8. The overall distribution of semantic formulas in the natural data: Compliments

\begin{tabular}{|lccc|}
\hline \hline Semantic Formulas & Raw Tokens (\%) & Singleton (\%) & Combination (\%) \\
\hline Unbound & $242(62.05)$ & $112(46.28)$ & $130(53.72)$ \\
Explicit Compliment & $14(3.59)$ & $14(100)$ & 0 \\
Implicit Compliment & & & \\
& & & $47(100)$ \\
Bound & $47(12.05)$ & $14(100)$ \\
Explanation & $14(3.59)$ & $1(100)$ \\
Information Question & $1(0.26)$ & $39(100)$ \\
Future Reference & $39(10.00)$ & \\
Contrast & 0 & & \\
Advice & 0 & & \\
Request & & & \\
& & & \\
Non-Complimentary Replies & 0 & & \\
Non-Compliment & 0 & $1(100)$ \\
Opt Out & & & $1(100)$ \\
Additional Semantic Formulas & $24(6.15)$ & \\
Conversation Opener & $8(2.05)$ & \\
Address Term & $1(0.26)$ & & \\
Appreciation Token & $390(100)$ & & \\
\hline Total & & & \\
\hline \hline
\end{tabular}

(15) (Researcher running into an acquaintance for the first time after a long absence):

1 Researcher: 吚, 你 好。

ei4 ni4 xao4

(Particle) you good

'Hi, how are you?'

2 Acquaintance: 喔你好。听说你回来了, 还一直 
o4 ni4 xao4 t'in1 so2 ni4 xui2 le2 lo
(Particle) you good hear say you back (Tens

xe2 ji2 tși2

(Particle) you good hear say you back (Tense Marker) still all the while 没见到你。年轻了, 比以前还年轻。 mou1 tce3 tao3 ni4 nien2 tc ‘'in1 lo, pi4 ji4 t6،en2 ce2 nien2 t6 ‘in1 not see you young compare before even young 'Hi, how are you! (I) heard you were back but didn't see you. (You look) young, even younger than before.' [Conversation Opener] [Explicit Compliment]

(16) (A woman said to a male friend):

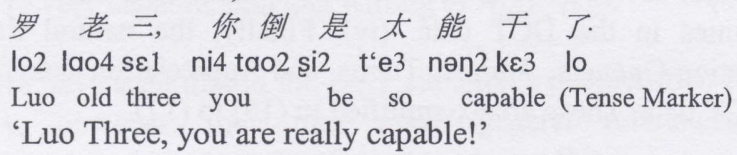

[Address Term] [Explicit Compliment]

(17) (A woman, who had been offered some sauerkraut by a friend, said to her friend):

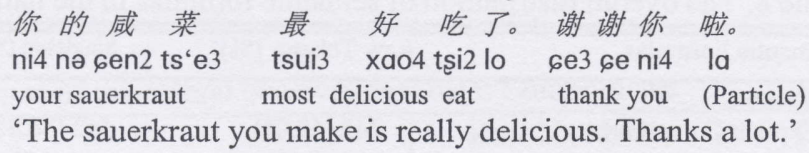

[Explicit Compliment] [Appreciation Token]

The finding of the use of Conversation Openers and Address Terms with compliments in natural settings highlights the fact that compliments are part and parcel of real life conversations and therefore do not always occur by themselves, as some studies based on DCT data alone might unintentionally suggest (e.g. Ye, 1995).

More importantly, while compliments and their bound semantic formulas may occur consecutively in the observational data as they do in the DCT, such as in (18), it is also common to see them spread over several turns, such as in (19):

A 埃, 这个录音机好了, 小巧玲珑。

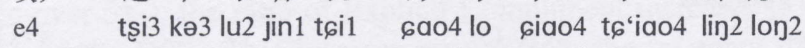

(Particle) this tape-recorder good small dainty

'Wow, this tape-recorder is good: Small and dainty.'

[Explicit Compliment] [Explanation]

B 恩, 方 便。

n2 fap1 pien3

(Particle) convenient

'Yeah, (it's) convenient/easy to carry.'

A. 吆, 你 - 回来这个家又干干净净的了。

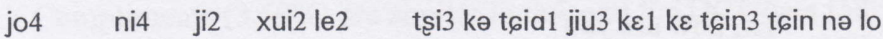

(Particle) you as soon as come back this house again clean (Tense Marker) 
'As soon as you come back, this place becomes clean again.'

B. 不会嘛。

pu2 xui3 ma

not possible (Particle)

'Not really.'

A. 1 X.C. 住在这点的时候连地板的花纹 tşu3 tse 3 tşi3 tiə4 nə și2 xou3 lien2 ti3 pe4 nə xual wən2 X.C. live here time even floor wooden pattern

2 都看不见了, 灰蒙蒙呢。

tou 1 ' $\varepsilon 3$ pu2 tcen 3 lo xuil mon 2 mon 2 nə

even see not (Tense Marker) dusty (Particle)

'When X.C. lived here, (you) couldn't even see the patterns of the wooden floor: (It was all) dusty.'

B. (笑笑) (Smile)

Here in (19), there is a sequence of Compliment $->$ Disagreement $->$ Contrast $->$ Opt Out (with a smile). Such interactive exchanges or negotiations of compliments and compliment responses have not been found in any DCT-based studies no matter how creative/imaginative a DCT respondent can be. It is therefore one of the constraints of the DCT questionnaire.

From the discussions of the DCT data and the natural data, we can say with certain confidence that compliments in Kunming Chinese most frequently take the form of an explicit statement either alone or in combination with an explanation, or a question, or a contrast, usually with the compliment preceding the other elements. Indirect compliments, on the other hand, occur by themselves most of the time. Compliments are also often embedded in conversations and may come with conversation openers or address terms.

\subsubsection{Personal focus of compliments in Kunming Chinese}

All replies that were categorised as one of the two unbound semantic formulas are analysed in terms of whether the subject is first person, second person, third person/impersonal, or a combination of two or more of these, or dropped altogether. Tables 9 and 10 summarise the DCT and natural data respectively.

Table 9. Distribution of personal focus in DCT data

\begin{tabular}{|lcccccc|}
\hline \hline & $1^{\text {st }}$ Person & $2^{\text {nd }}$ Person & $3^{\text {rd }}$ Person/Impersonal & Combination & Dropped & Total \\
Raw Score & 39 & 703 & 703 & 18 & 402 & 1865 \\
Percentage & 2.09 & 37.69 & 37.69 & 0.97 & 21.55 & 99.99 \\
\hline \hline
\end{tabular}


Table 10. Distribution of personal focus in natural data

\begin{tabular}{|lcccccc|}
\hline \hline & $1^{\text {st }}$ Person & $2^{\text {nd }}$ Person & $3^{\text {rd }}$ Person/Impersonal & Combination & Dropped & Total \\
Raw Score & 6 & 46 & 165 & 8 & 31 & 256 \\
Percentage & 2.34 & 17.97 & 64.45 & 3.13 & 12.11 & 100 \\
\hline \hline
\end{tabular}

Table 9 shows that among the different possibilities, the second person 'you' and third person/impersonal focuses have the highest percentages $(37.69 \%)$ in the DCT data. (20) and (21) are examples:

(20) [Scenario 7, new hair cut]

你越长越俏了。

you more grow more attractive (Tense Marker)

'You're getting more and more attractive.'

(21) [Scenario 1, bright child]

(Written DCT) (Second Person Focus, 43-M-O-C)

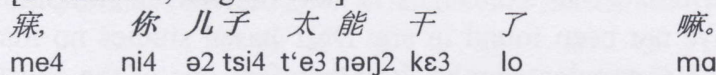

(Particle) you son so capable (Tense Marker) (Particle)

'Wow, your son is so very capable (Particle)!'

(Oral DCT) (Third Person Focus, 55-F-Y-H)

Subject deletion is also common, accounting for $21.55 \%$ of the DCT compliments:

(22) [Scenario 1, bright child]

1 呵哟, 这么聪明才这么大就能做二年级的

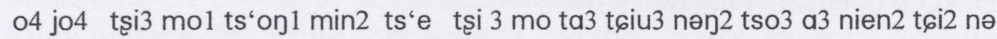

(Particle) so bright only this big already can do 2 grade

2 算术题, 以后一定有发展前途。

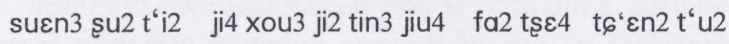

maths problem future must have develop future

'Wow, (he is) so bright, (he) can do grade two maths when (he is) so young.

(He) must have a bright future later.' (Oral DCT) (Subject Deletion, 173-F-O-H

On the other hand, respondents rarely pay compliments from a first person perspective (only about $2 \%$ of the time) or combine 2 or more focuses. The very few times when the first person does appear are when ' $\mathrm{I}$ ' is used in the syntactic pattern of ' $I$ $\{$ think/feel $\}+$ subordinate clause'. This is very different from American and New Zealand English, where the first person focus appears predominantly in the syntactic pattern of 'I \{like/love\} NP' (cf. Holmes, 1988a; Wolfson, 1989).

The natural data, however, present a somewhat different picture from the DCT data in the use of second person and third person/impersonal focuses although the first person and combination of two or more focuses remain rare. We see in Table 10 that the frequency of the second person focus drops to $17.97 \%$ in the natural data from the $37.69 \%$ of the DCT whereas the frequency of the third person/impersonal focus almost 
doubles, from $37.69 \%$ in the DCT to $64.45 \%$ in the natural data. A closer look at the data reveals that the high frequency of the third person/impersonal focus is mainly brought about by the fact that speakers of Kunming Chinese tend to emphasise the object of compliment by placing it in the prominent subject position, especially when the object of compliment involves the compliment-receiver's ability, possession, child, or attire. Examples (23) to (26) illustrate this point:

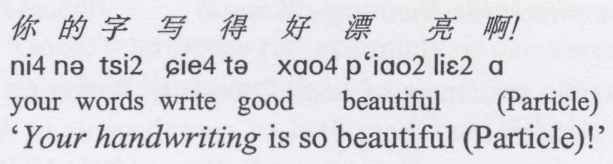

(Ability)

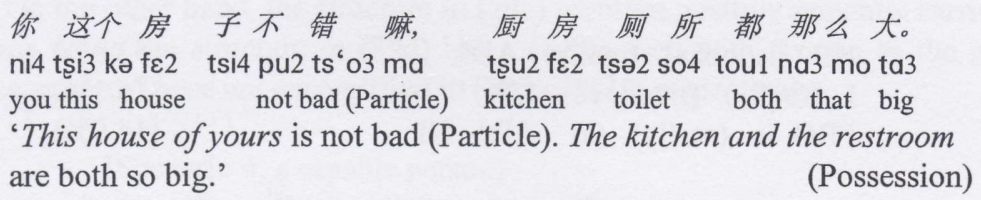

(Possession)

(25) 宊, 这个儿子长得太漂亮了。

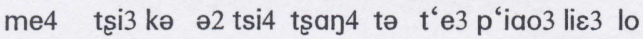

(Particle) this son grow so beautiful (Tense Marker)

'Wow, this son (of yours) is so handsome.'

(Child)

（26）你这个裙子穿起还蛮好看的

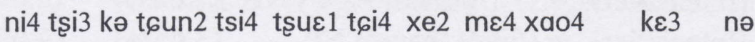
you this dress wear still quite good looking (Particle)

'This dress of yours looks good (on you).'

(Attire)

The second person focus, on the other hand, is mostly restricted to compliments paid on the compliment-receiver's young looking or healthy looking appearance, as in (27):

$$
\begin{aligned}
& \text { 喔, 你看到身体还好嘛, 怪精神的. } \\
& \text { o4 ni4 } k^{\prime} \varepsilon 3 \text { tao4 sain1 t'i } 4 \text { xe2 xao4 ma kue3 tçin1 şain2 nə } \\
& \text { (Particle) you look health still good (Particle) quite energetic (Particle) } \\
& \text { 'Wow, you look to be in good health (Particle), very energetic.' } \\
& \text { (Appearance) }
\end{aligned}
$$

Table 11. Distribution of topic/object of compliment in natural data

\begin{tabular}{|ccccccc|}
\hline \hline Ability & Appearance & Possession & Child & Attire & Whole Person & Total \\
65 & 58 & 48 & 47 & 29 & 9 & 256 \\
$25.39 \%$ & $22.66 \%$ & $18.75 \%$ & 18.36 & 11.33 & 3.52 & 100 \\
\hline \hline
\end{tabular}


If we look at the distribution of objects or topics of compliments in the natural data shown in Table 11, we see that ability, possession, child, and attire together account for about $73 \%$ of the compliments. Since most compliments involving these topics have the object of compliment in the subject position, it is not surprising that over $64 \%$ of the 256 real life compliments have the third person/impersonal focus.

\subsubsection{The syntactic patterns of compliment in Kunming Chinese}

As in American English, the syntactic structures of compliments in Kunming Chinese turn out to be very formulaic. To recapitulate, about $85 \%$ of compliments in American English fall into the following three syntactic patterns (see Wolfson, 1981: 122):

$\begin{array}{lll}28(a) & \mathrm{NP} \text { [is/looks] (really) ADJ } & (53.6 \%) \\ 28(\mathrm{~b}) & \mathrm{I} \text { (really) [like/love] NP } & (16.1 \%) \\ 28(c) & \text { PRO is (really) (a) ADJ NP } & (14.9 \%)\end{array}$

In Kunming Chinese, about $94 \%$ of both the DCT and the natural compliments fall into one of four syntactic structures and the similarities between the DCT and natural data are extremely striking:

$\begin{array}{llll}29(\mathrm{a}) & \text { (NP) (Intensifier) ADJ/VERB (Object) } & \underline{\text { DCT }} & \underline{\text { Natural }} \\ 29(\mathrm{~b}) & \text { (NP) } \mathrm{V} \text { 得 (/tə2/, complement particle) Complement } & (21.82 \%) & (19.14 \%) \\ 29(\mathrm{c}) & \text { (NP) }\{\text { Agent }\} \text { (Intensifier) }) \text { 是 个(/si2 kə/ 'is a') NP } & (7.02 \%) & (5.86 \%) \\ 29(\mathrm{~d}) & \text { (NP) }\{\text { Agent }\} \text { (Intensifier) }) \text { 有 (/jiu4/ 'have') NP } & (3.65 \%) & (4.69 \%)\end{array}$

Total

$93.94 \% \quad 93.75 \%$

The structure in (29a) is the most productive of all, accounting for over $60 \%$ of the compliments. The obligatory element of this structure is the predicate, which can be either an adjective/stative verb or a verb, with or without an intensifier. An object may be optionally present if the predicate is a verb. An NP denoting an agent or an object may or may not appear in the subject position. (30) is an example of this structure:

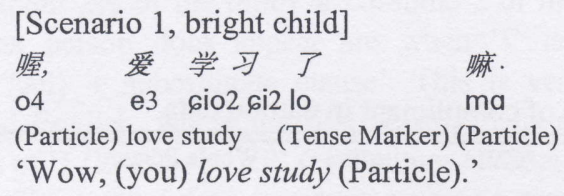

The structure in (29b) involves an NP subject, present or absent, followed by a verb accompanied by the complement particle 得 (/tə2/) with an obligatory complement. This complement functions very much like an adverbial in English: 
(31) [Scenario 11, newly renovated house]

1 麻, 你家太, 装修得太好了踱, me4 ni4 jia1 t'e3 tşe1 ciul to t'e3 xao4 lo ma (Particle) you house so renovate so good (Tense Marker) (Particle)

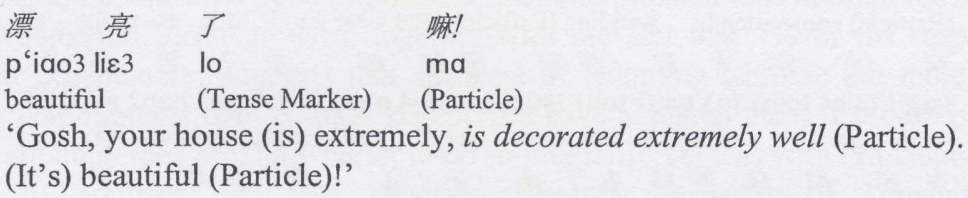

(Oral DCT) [Explicit Compliment] (70-F-M-H)

On the other hand, the structure in (29c) involves positive semantic carriers that are nouns while the structure in (29d) has a stative verb with a noun as the positive semantic carrier. These are exemplified in (32) and (33) respectively:

$$
\begin{aligned}
& \text { [Scenario 4, a capable person] } \\
& \text { 你 真是 个 多 面 手。 } \\
& \text { you really are one many-sided hand } \\
& \text { 'You're really a many-sided hand.' }
\end{aligned}
$$

(Written DCT) (Pattern 13c, 43-M-O-C)

[Scenario 9, new carpet]

你 很 有 眼光。

you very have eyesight

'You have a very good taste.' (Written DCT) (Pattern 13d, 171-F-O-H)

The most common structure of (29a) in Kunming Chinese is similar to the 'NP is/looks (really) ADJ' pattern of (28a) found most often in American English whereas (29c) of Kunming Chinese resembles (28c) of American English. However, (28b) of American English has only one occurrence in Kunming Chinese partly because most Chinese compliments have third person/impersonal and second person focuses and partly because expressions such as 'I like' or 'I love NP' may cause such mis-interpretations as 'I want your NP'. They are thus avoided in Kunming Chinese when possible.

\subsection{Compliment responses}

\subsubsection{An overall view of compliment responses in the DCT data}

Like compliments, there are 2100 compliment responses elicited (175 subjects x 12 scenarios), which yield a total of 2900 tokens of semantic formulas. Table 12 summarises the distribution of the 12 semantic formulas. It shows that Explanation is the predominant semantic formula of all in that it accounts for over $43 \%$ of all the semantic formulas used. (34) is an example of Explanation that appeared in the oral DCT: 
(34). [Scenario 17, in response to "Wow, you're dressed up so beautifully" at a wedding]

1 么来参加婚礼嘛要穿讲究点大家都

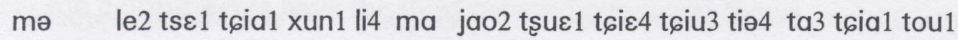
(Particle) come attend wedding (Particle) need wear good little everyone all

2 穿讲究大家都穿得好嘛也不能说是

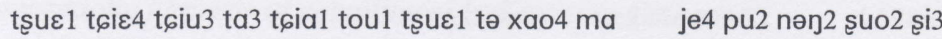
wear good everyone all wear good (Particle) also cannot say be

3 来参加你的婚礼了嘛还, 恩穿得那个不 le2 t6 ' $\varepsilon 1$ tcia1 ni4 nə xun1 li4 lo ma xe2 n tşuع1 tə nə3 kə pu2 come attend your wedding (Particle) still (Particle) wear that not

4 整齐么, 就不美观了.

tşain4 t6 'i2 mə tçiu3 pu2 mei4 kuع1 lo

tidy (Particle) then not good see (Particle)

'Coming to (your) wedding (Particle), of course, (I) want to dress up a little bit. Everybody dresses up, everybody dresses up nicely (Particle), and (I) can't come to (your) wedding (Particle) and still, um, not dressed neatly. That wouldn't be visually pleasant.'

(Oral DCT) [Explanation] (76-F-O-J)

Table 12. An overall view of the DCT data: Compliment responses

\begin{tabular}{|lcc|}
\hline \hline Semantic Formulas & Raw Tokens & Percentage (\%) \\
\hline Acceptance & 203 & 7.00 \\
Explanation & 1255 & 43.28 \\
Return & 217 & 7.48 \\
Appreciation & 65 & 2.24 \\
Upgrade & 14 & 0.48 \\
Reassignment & 36 & 1.24 \\
Invitation & 44 & 1.52 \\
Suggestion & 30 & 1.03 \\
Confirmation Seeking & 89 & 3.07 \\
& & 16.55 \\
Downgrade & 480 & 12.38 \\
Disagreement & 359 & 3.72 \\
Opt Out & 108 & $99.99 \%$ \\
\hline Total & 2900 & \\
\hline \hline
\end{tabular}


As shown in (34), Explanations can imply acceptance of a compliment even though the respondent does not necessarily state so overtly. So in the above example, the respondent did not say 'Yes, my dress is nice'. However, by explaining that since everybody else is dressed up, I cannot do otherwise, she is saying indirectly that yes, I am dressed up, but for a good reason. The fact that Explanations account for nearly half of the semantic formulas used, together with the fact that $7 \%$ of the responses are explicit acceptances, suggests that speakers of Kunming Chinese are more ready to accept compliments than cultural stereotypes have assumed them (Chinese in general) to be, although they probably prefer to do so implicitly, such as with Explanations.

In contrast, the two rejection semantic formulas of Downgrade and Disagreement account for only about $29 \%$ of all the compliment responses:

(35) [Scenario 22, in response to "You're really nice and kind. I admire and respect you very much"]

徔, 差不多, 都是一样的。

e4 tsal pu2 tuol toul și3 ji2 je3 nə

(Particle) difference not many all be same

'Well, (we're) more or less the same, (everybody's) the same.'

[Downgrade] (5-M-Y-J)

(36) [Scenario 21, in response to "Your place is always so nice and clean!']

干净哪样还不是老样子。

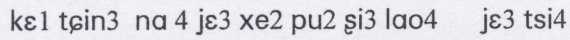

clean what still not be old appearance

'(It's) not at all clean (Particle); (it's) still the same as usual.'

[Disagreement] [Downgrade] (158-F-M-H)

Table 13. Chen's findings about Chinese compliment responses (1993: 56)

\begin{tabular}{|c|c|c|c|}
\hline Strategy type & & $\mathrm{N}$ & $\%$ \\
\hline \multicolumn{4}{|l|}{ Super Strategy 1: Rejecting } \\
\hline 1. Disagreeing and denigrating & & 148 & 50.70 \\
\hline 2. Expressing embarrassment & & 76 & 26.10 \\
\hline \multirow[t]{2}{*}{ 3. Explaining } & & 55 & 18.83 \\
\hline & Total & 279 & 95.73 \\
\hline \multicolumn{4}{|l|}{ Super Strategy 2: Thanking and denigrating } \\
\hline 4. Thanking and denigrating & & 10 & 3.41 \\
\hline \multicolumn{4}{|l|}{ Super Strategy 3: Accepting } \\
\hline 5. Thanking only & & 3 & 1.03 \\
\hline Total & & 292 & 100.00 \\
\hline
\end{tabular}


This low frequency of rejection is quite interesting as denying a compliment and denigrating oneself to show one's modesty have been regarded as the norm of compliment responses in Chinese and have been found to be true in Chen's (1993) study. If we compare what we see in Table 12 with Chen's findings in Table 13, we will see a world of difference. Here as much as $95.73 \%$ of the compliment responses belong to the super strategy of Rejecting as compared to $29 \%$ of the present study. Even if we exclude the ambiguous semantic formula of Explaining from the Rejecting category in Table 13 (as we have shown earlier that Explanations can be interpreted as acceptances in some contexts), the rejecting rate in Chen's study is still very high, over $70 \%$. We will discuss this difference in the Discussion and Implications section.

\subsubsection{An overall view of compliment responses in the natural observational data}

The way compliments are responded to in the natural observational data is summarised in Table 14.

Table 14. An overall view of the natural data: Compliment responses

\begin{tabular}{|lcc|}
\hline \hline Semantic Formulas & Raw Tokens & Percentage (\%) \\
\hline Acceptance & 40 & 15.63 \\
Explanation & 40 & 15.63 \\
Return & 9 & 3.52 \\
Appreciation & 5 & 1.95 \\
Upgrade & & 1.17 \\
Reassignment & 3 & 2.73 \\
Invitation & & 14.84 \\
Suggestion & 7 & 19.14 \\
Confirmation Seeking & & 25.40 \\
Downgrade & 38 & $100.01 \%$ \\
Disagreement & 49 & \\
Opt Out (with a smile) & 65 & \\
\hline Total & 256 & \\
\hline
\end{tabular}

Similar to the DCT data, we see that the frequency of the two rejecting semantic formulas of Downgrade and Disagreement is still rather low compared to Chen's (1993) findings, at about $34 \%$. This not only reinforces the earlier suggestion that speakers of Kunming Chinese are less conventional than they are thought to be, but may also indicate certain dialectal differences or may even have certain methodological implications (see the discussion section). In addition, Table 14 also shows some differences between the natural observational data and the DCT data. One of these differences is a lower frequency of Explanations in the natural data than in the DCT data $(15.63 \%$ vs. $43.28 \%)$ and a higher acceptance rate $(15.63 \%$ vs. $7 \%)$. In the conversation of (37), for example, $\mathrm{C}$ shows no hesitation in accepting the compliment he receives: 
(37).

A. Z.M 是个学语言的天才学哪样像哪样。

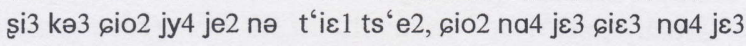

Z.M be a learn language genius learn what resemble what

'Z.M is a genius in language learning. Whatever he learns he learns it well.'

B. 埃。

e4

(Particle)

'Yes.'

C. 我还是可以的。

wo4 $\mathrm{xe} 2$ si3 $\mathrm{k}^{6} 04 \mathrm{ji} 4$ nə

I still be OK (Particle)

'I'm OK.'

Another difference between the observational data and the DCT data is the noshow of Appreciations, Reassignments, and Suggestions. It is worth noting that the Appreciation type of replies such as 'Thank yous' has been found in the DCT data of the present study as well as in the other two studies on compliment responses in Chinese, i.e. Chen's 1993 and Ye's 1995 studies, both of which are DCT based. The fact that it is NOT found at all in the natural observational data may suggest that subjects may write down in the DCT questionnaire something which they THINK they may say in a certain situation but which they do not actually say in real life situations. It has been reported that saying 'Thank you' in response to a compliment is the standard norm in the American culture (cf. Herbert, 1986), but it is something not usually found in Kunming Chinese. (38) below is the opinion of an interviewee about the use of 'Thank yous' in compliment responses in Kunming Chinese:

1 Interviewer: 那 别人 如果称赞 你会不会 说, 比如 说 then others if compliment you will not will say for example say

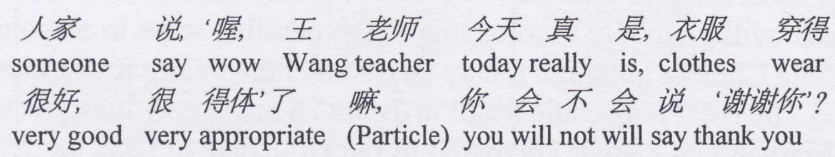

'Then if someone compliments you, would [you] say, for instance, if someone says, 'Wow, today teacher Wang looks really, you're dressed up so nicely and appropriately' (Particle), would you say 'Thank you'?'

Interviewee: 一般 不 会.

usually not will 


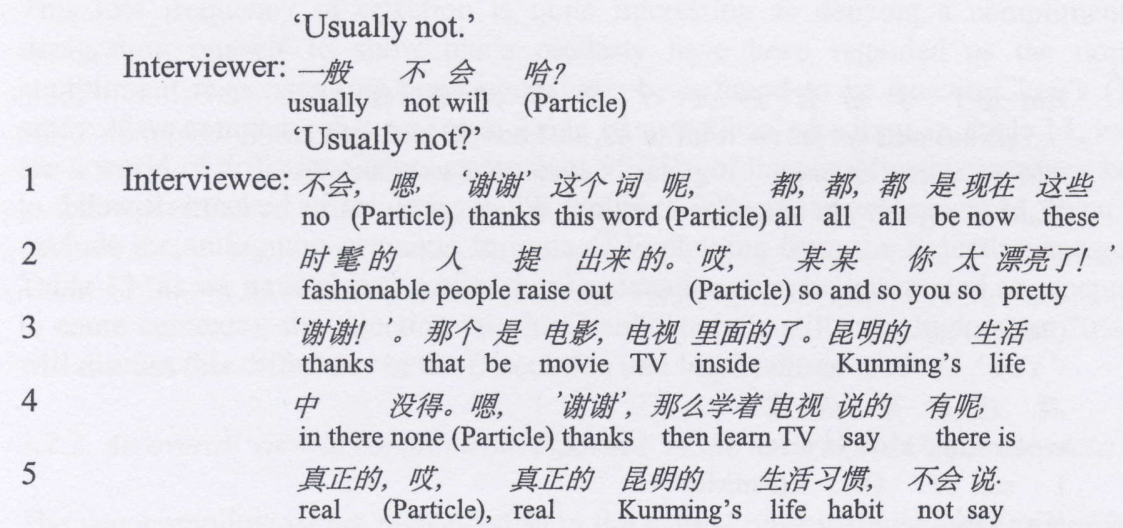

'The word 'Thank you' (Particle) is all, all, all, made up by some fashionable people. 'Well, so and so, you're beautiful!', 'Thank you'. This only appears in movies and TV. It doesn't exist in the everyday life of Kunming. Um, indeed [people] may copy what's in TV and say 'Thank you'. Real, um, real Kunming customs don't do it.'

As the interviewee comments, 'Thank you' is a new and fashionable thing to say in response to a compliment as a result of western influence but it is still not common in Kunming Chinese. Maybe what we see in the DCT is a change in progress in the pragmatics of the dialect: Speakers of the dialect are tempted to shift towards the 'Thank you' type of response to compliments and think they may say so in some situations. So they put it down in the DCT. However, since this is something so new, it may not have registered in people's mind yet. That is perhaps why we are not seeing it in the observational data yet. We can probably predict that the 'Thank you' type of response will gradually become one of the possible ways to respond to compliments in Kunming Chinese although it may take some time before it takes its root in the dialect.

The most noticeable result in Table 14 is the very high frequency of Opt Outs in the observational data as compared to the DCT data $(25.4 \%$ vs. $3.72 \%)$. What is more, all the Opt Outs in the observational data are accompanied by a smile, such as in (39):

(39). (Upon A's entering the apartment of B)
A. 你家太干净了麻。
ni4 tçia1 $t^{6} \mathrm{e} 3 \mathrm{k} \varepsilon$ t $\operatorname{c} \sin 3$ lo $\mathrm{ma}$
you house so clean (Particle)
'Your house is so clean.'

B. (笑笑)

(Smile) 
The fact that a quarter of the 256 compliments in the observational data are replied in this manner shows that this is a very important strategy speakers of this dialect use. Maybe smiling away a compliment one receives can resolve the conflict of being modest and disagreeing with the interlocutor. The virtue of being modest in the Chinese tradition requires one to deny a compliment one receives, but in order to achieve this goal, one has to disagree with the compliment one receives, thus threatening the complimenter's positive face (c.f. Brown and Levinson, 1987). An Opt Out with a smile allows the complimentee to accept the compliment gracefully without risking the complimenter's face.

\section{Discussion and Implications}

\subsection{Compliments and compliment responses in Kunming Chinese}

We have seen in the previous section that speakers of Kunming Chinese tend to pay compliments explicitly in most of the complimenting situations. Other times but much less frequently, they either make general statements or make non-complimentary remarks.

If we compare findings of the present study with those of Ye's 1995 study presented in Table 15, we will see some differences between the two studies. Specifically, apart from Implicit Compliments, which are used to about the same extent in both studies and in different types of data, Ye's study has a lower frequency of Explicit Compliments than the two types of data of the present study. This lower frequency is brought about directly by the high frequencies of Non-Complimentary Replies and Opt Outs. While it is not clear why as much as $23.9 \%$ of Ye's DCT questions did not receive any replies and $13.6 \%$ of the other replies are noncomplimentary in nature, what we can say with confidence is that speakers of Kunming

Table 15. Comparison of compliments between present study and Ye's 1995 study

\begin{tabular}{|c|c|c|c|c|}
\hline & & $\begin{array}{c}\text { Present study: } \\
\text { Natural data (\%) }\end{array}$ & $\begin{array}{c}\text { Present study: } \\
\text { DCT data (\%) }\end{array}$ & $\begin{array}{c}\text { Ye 1995 } \\
(\%)\end{array}$ \\
\hline \multirow{2}{*}{ Compliments } & Explicit Compliments & 94.53 & 83.10 & 56.6 \\
\cline { 2 - 5 } & Implicit Compliments & 5.47 & 5.71 & 6.0 \\
\hline \multirow{2}{*}{$\begin{array}{c}\text { Non-complimentary } \\
\text { Replies }\end{array}$} & Non-Compliments & 0 & 7.76 & 13.6 \\
\cline { 2 - 5 } & Opt Outs & 0 & 3.43 & 23.9 \\
\hline \multicolumn{2}{|c|}{100} & 100 & 100 \\
\hline
\end{tabular}

Chinese tend to be explicit when they pay compliments. The existence of NonCompliments and Opt Outs in both the DCT data of the current study and Ye's DCTbased study (although not in the natural data of the present study) also suggests that offering a compliment in a complimenting situation is not obligatory in both Mandarin and Kunming Chinese. There are cases where somebody notices something nice and positive and yet refrains from issuing a compliment. However, such non-complimentary 
behaviour has not been reported in the literature of compliments in other languages as most such studies use ethnographically collected data in their analyses (e.g. Herbert, 1991; Holmes, 1988a; Wolfson, 1981) and have therefore noted down compliments only when they occur. As a result, non-complimentary remarks or absence of compliments in complimenting situations have necessarily escaped the attention of researchers, showing the constraints of using one data source for pragmatic studies.

Turning now to compliment responses, we have found that speakers of Kunming Chinese do not reject compliments as much as what the stereotypes tell us. In fact, the rejection rates for the natural as well as the DCT data in the present study are both very low compared with Chen's (1993) findings. If we only look at Acceptance, Downgrade and Disagreement (pure accepting and rejecting) and disregard the other semantic formulas as the latter can be interpreted either as acceptances or rejections depending on the context they occur, we get Table 16.

Table 16. Comparison of compliment responses between present study and Chen's 1993 study

\begin{tabular}{|c|c|c|c|}
\hline & $\begin{array}{c}\text { Present study: Natural } \\
\text { data (\%) }\end{array}$ & $\begin{array}{c}\text { Present study: } \\
\text { DCT data (\%) }\end{array}$ & $\begin{array}{c}\text { Chen 1993 } \\
(\%)\end{array}$ \\
\hline Accepting & 15.63 & 7.00 & 1.03 \\
\hline Rejecting & 33.98 & 28.93 & 95.73 \\
\hline Opt Outs & 25.40 & 3.72 & 0 \\
\hline
\end{tabular}

(Figures in the last column are adapted from Chen, 1993: 64)

Here we see the acceptance rate is the highest in the natural data and lowest in Chen's study while the rejection rate is over $95 \%$ in Chen's study. This has led Chen to claim that the Modest Maxim carries more weight than the Agreement Maxim in the Chinese culture and that "the norm of Chinese society ... is to be modest" by rejecting compliments they receive (pp. 66-67). While this may be true in Chen's study, it is certainly not quite so in the present study. In the natural data, for instance, a quarter of the responses are Opt Outs with a smile. We have seen in the result section that these are actually non-verbal acceptances of compliments, a strategy people use to avoid the conflict between the Modest Maxim and the Agreement Maxim. If that is the case, then we can perhaps interpret the difference between Chen's study and the present study as a possible dialectal difference between Mandarin Chinese and Kunming Chinese. That is, while Mandarin speakers reject compliments they receive, speakers of Kunming Chinese are equally likely to reject or accept compliments either verbally or nonverbally. In other words, speakers of Kunming Chinese are gradually beginning to deviate from the tradition of disagreeing to or downgrading a compliment to a more accepting attitude, probably because of western influence through movies and the media. We have seen earlier in (38) the emergence of 'Thank yous' as a result of such 
influence. The following excerpt from my interview with a respondent reinforces this claim of western influence and the changes such an influence entails:

(40)

\title{
Interviewer: 现在西方 那些 影响 还是大了嘛, 嘎, 我觉得?
} now western those influence still big (Particle), right, I feel

'Now influences from the west are pretty big (Particle), right, I feel?'

Interviewee: 哎, 影响还是大, 确实是大的。像 以前有些 话, 嘎, (Particle) influence still big indeed be big like before some words (Particle)

\begin{abstract}
从 那些 西方的文化呵，各种 传播 方式呵，它的语言方面，给我们 from those western cultures (Particle) different media method its language give us 这种, 不管 哪点的人, 带来的影响都还是大呢。讲说可能我们 this kind no matter where people bring influence all be big (Particle) say maybe we 现在这种赞扬的方式跟比我们大几十岁的人完全是 now this compliment way compare we older some decades people completely be 两回事, 待人的 态度了嘛, 都是有影响的, 实际上从 这些 two thing treat people attitude (Particle) all have influence, in fact from these 录相带 呵, 这些, 各方面讲, 甚至 有时候一句那种比较 movies (Particle) these all aspects say, even sometimes one comparatively 流行点的口头禅呵那些, 嘎, 从港台片阿, 从西方的 fashionable pet phrase these, (Particle), from Hong Kong Taiwan movies, from western 从这些你听了以后, 就可能学着说了。 from these you hear after, then maybe learn say (Tense Marker)
\end{abstract}

'Well, the influence is rather big, indeed it's big. Like there were some expressions in the past, right, for example, from western civilisations, through all kinds of channels, their languages, have had great influence on people like us, people everywhere. For example, our way of compliment is totally different from that of people who are a few dozens of years older than we are. Their attitudes towards people have all kinds of impact, in fact. From things like video tapes, in all aspects, even a popular pet phrase, things like that, right, from Hong Kong and Taiwan movies, from the west, when you hear them, you'll learn to say them.'

\subsection{Methodological implications}

\subsubsection{Observational data vs. DCT data}

This study has uncovered some important differences between the data-gathering methods of natural observation and the DCT.

Firstly, although some semantic formulas found in the DCT are also found in the observational data, there are semantic formulas used in the DCT that are NOT found in the observational data and vice versa. For example, in compliments, Advice, Request, Non-Compliment and Opt Out found in the DCT did not show up at all in the 
observational data. On the other hand, Conversational Opener, Address Term and Appreciation Token that appeared in the observational data were not found at all in the DCT data. In compliment responses, Appreciation, Reassignment and Suggestion that showed up in the DCT did not appear in the observational data while Opt Out with a smile had a much higher frequency in the observational data than in the DCT data. Such additional information from the observational data enables us to look at the compliment event as part of our everyday interactions (instead of an isolated language phenomenon) and provides us important insights into the function of the compliment event in our everyday life. The differences show that perhaps DCT respondents are just reporting what they think they would or should say or do in a certain situation and not what they actually do in real life. In this sense, observational data will be a better choice if the purpose of a study is to investigate real life complimenting activities in a speech community.

Secondly, DCTs tend to elicit monologic compliments and compliment responses whereas observations yield longer exchanges where the speech event of compliment occurs with conversation openers and address terms and may be realised in several turns through negotiations and reinforcement, such as in (19). This phenomenon has also been reported in Beebe and Cummings (1996) and Yuan (2001). Undoubtedly, it gives observational data the edge of being closer to life than DCT data do.

However, observational data may not contain situations where a compliment fails to show up in a complimenting situation whereas DCTs can do the job. To recapitulate, some DCT respondents opted out in some of the complimenting situations whereas no such case was recorded in the observational data or in any study that is based on observational data such as Herbert, 1991 and Wolfson, 1983. This is because researchers only write down compliment exchanges as they occur. Such a practice can be problematic since different observers may have a somewhat different definition of what makes a compliment and therefore what gets observed and noted down may vary from researcher to researcher. In addition, the gender, age and other personal background of the researcher may place a limit on who gets observed. In the present study, for example, a majority of the people observed fall into the category of females in their 30 s and $40 \mathrm{~s}$. As a result, the data might be biased. In this sense, then, the DCT has certain advantages over natural observation in that it can be more controlled/balanced and that the researcher would know if an opt out situation occurs.

The similarities and differences between the DCT and observational data show, on one hand, the value of the DCT as a basic tool to get an initial understanding of a speech act/event in a speech community as respondents will tell you how they think a speech act is done in their speech community. However, to get an authentic picture of how the speech act/event is actually executed in real life, natural data will have to be used, that is, if you are willing to accept the possibility of bias mentioned in the previous paragraph. ${ }^{6}$ Ideally, if there is enough time and manpower, a combination of different data-gathering methods should be used so that the results will complement and compensate for each other.

${ }^{6}$ See Beebe (1994) and Yuan (2001) where they caution the lack of accuracy in the wording of what is noted down in observational data. 


\subsubsection{Categorisation of semantic formulas}

Another important contribution of the present study is the categorisation of the compliment semantic formulas into unbound and bound groups. Most studies on compliments to date (e.g. Herbert, 1991; Holmes, 1988a; Wolfson, 1981, etc.) report only compliments that contain one single utterance containing a positive semantic carrier. The current data pool of Kunming Chinese contains many instances of compliments that consist of not only the central part with the positive semantic carrier, but also some other elements such as information questions, explanations, and so on. Ignoring these adjunct elements would obscure the picture of how compliments are paid in the dialect.

The division of unbound and bound semantic formulas not only differentiates the core of a compliment from other supportive moves, it also makes the coding system more comparable to other speech acts. Requests, for instance, are often coded as Head Acts and Adjuncts (cf. Blum-Kulka \& Olshtain, 1984). The unbound and bound semantic formulas in compliments resemble the Head Acts and Adjuncts in requests in some ways. The difference, though, lies in the fact that an Adjunct in requests (such as an Explanation) can become a Head Act (an indirect request) in the absence of an explicit request. However, a bound semantic formula in compliments such as an Information Question can not be coded as an unbound semantic formula (or compliment) since an utterance without any explicit or inferable positive connotation can be ambiguous in meaning.

Although the categorisation of unbound and bound semantic formulas is not always required for all speech acts (it is not relevant for compliment responses, for example, since anything following a compliment is a response to it), it may be useful for other speech acts. Take apologies as an example. The CCSARP project uses five criteria to determine whether an utterance is an apology: (a) The utterance has an illocutionary force indicating device (IFID); or (b) It contains an explanation; or (c) The speaker takes on responsibility for an offence; or (d) The speaker provides an offer of repair; or (e) The utterance contains a promise of forbearance (cf. Blum-Kulka \& Olshtain, 1984). (41) to (45) are examples of the five categories.

I'm so sorry (that) I'm so late.

I'm so forgetful.

The bus was late.

I'll pay for the damage.

This won't happen again.
(IFID)

(Taking on responsibility)

(Explanation)

(Offer of repair)

(Promise of forbearance)

(Source: Blum-Kulka \& Olshtain, 1984: 207-208)

However, it seems that only the IFID category can unambiguously make an utterance an apology whereas the other categories do not necessarily do so. 'The bus was late', for example, can imply that 'It's not my fault that I'm late. I'm late because the bus was late. So don't blame me'. In fact, the same utterance 'The bus is late' can be either apologetic or non-apologetic depending on the intonation, the intention of the speaker, 
the interpretation of the hearer and some other factors, but without any IFID or interviewing the speaker as well as the hearer, we cannot know. The same is true for information questions such as 'Where did you get that blouse?' in a complimenting situation. We cannot be sure it is a compliment until we have interviewed the speaker and the hearer since the question does not contain any positive semantic carrier. By following the bound-unbound coding system proposed in this study and categorising only the IFID as apologies (whereas the other 4 types have to co-occur with an IFID to be counted as an apology), we avoid such ambiguities and uncertainties. It seems then that the unbound-bound division of semantic formulas has some theoretical and methodological implications across different speech acts.

\subsection{Cross-cultural variation and implication}

Complimenting activities exist in perhaps most cultures in the world. One thing that has emerged from studies on this speech event is that compliments tend to be highly formulaic syntactically across different cultures, indicating that the speech act of compliment may have become highly routinised in different cultures (cf. Ye, 1995).

However, some differences have also emerged across different cultures. Firstly, the specific syntactic patterns used in each culture may vary. For example, although the structure '(NP) (Intensifier) ADJ/VERB (Object)' (which accounts for over $60 \%$ of the Kunming Chinese data) and the structure 'NP [is/looks] (really) ADJ' (which accounts for $53.6 \%$ of the American data) are similar, the 'I (really) [like/love] NP' structure is very rare in Kunming Chinese. In other words, compliments are rarely paid from the first person perspective in Kunming Chinese. This is because compliments such as 'This carpet looks great' sound more objective than 'I like the carpet' even though the latter occurs more frequently in American English (16.1\%, cf. Wolfson, 1981) and New Zealand English (15.9\%, Holmes, 1988a). The 'I like NP' pattern may also come across as an indirect request in Chinese and is therefore undesirable/embarrassing if that is not the intended illocution. (46) records such an incidence:

(46). (At B's home, A seeing B knitting something)

A. 这个蛮好看的。我喜欢这个颜色。

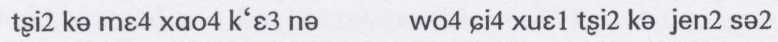
this quite good-looking (Particle) I like this colour 'This looks quite nice. I like the colour.'

B. 是围 巾三。咯想要? 要么我打好了给你。 si3 wei2 tcin1 se kə1 cis4 jao3? jao3 mə wo ta4 xao4 lo kə4 ni4 be scarf (Particle)want have want I finish(Tense Marker) give you 'It's a scarf. Do you want it? I'll give it to you when I finish it.'

A. 不 要。

pu2 jao3

not want

'No.'

B. 为 哪样 呢?

wei3 nai4 je3 nə 


\section{for what (Particle) \\ 'Why?' \\ A. 不好意思。 \\ pu2 xao4 ji3 sil \\ embarrassed \\ '(I'm) embarrassed.'}

The more 'Chinese' way is to pay compliments from a second person or third person/impersonal perspective.

Secondly, what is valued in one culture is not always valued in another. In Kunming Chinese (and perhaps in Chinese in general), for instance, being fat (but not excessively fat) is not necessarily a bad thing, especially to the older generations. ${ }^{7}$ The following is a compliment exchange between two friends in their late $30 \mathrm{~s}$ and early $40 \mathrm{~s}$ who haven't seen each other for a few years:

(47).

A. 你看你长得又白又胖呢。

ni4 $k^{6} \varepsilon 3$ ni4 tșe4 tə jiu3 pə2 jiu3 p' $\varepsilon 3$ nə

you see you grow so white so fat (Particle)

'Look at you, you are so fat with such a fair complexion.'

B. 哪个说, 你才是富态呢。

na4 kə suo2 ni4 ts'e si3 fu3 t‘e3 na

who say you be rich state (Particle)

'Not true. You are the one who are well-fed (look rich).'

Here being fat is interpreted as a sign of being rich and well-fed and the utterance is therefore interpreted as a compliment. Besides, having a fair (white) complexion is highly desirable too, especially for females. This value system forms a sharp contrast with western cultures where being fat is very bad and having a tan is something worth showing off.

Thirdly, the way compliments are responded to also differs from culture to culture. It has been shown in literature that people from western cultures tend to accept compliments with 'Thank yous' even though the extent to which they are willing to accept compliments may vary (cf. Herbert, 1986; Herbert \& Straight, 1989). While Chen's 1993 study finds that Mandarin speakers reject compliments 95\% of the time, the current study discovers that speakers of Kunming Chinese are more likely to accept compliments than Mandarin speakers. In addition, speakers of Kunming Chinese often accept compliments non-verbally, with a smile. This forms a sharp contrast to other cultures and even to Mandarin speakers, indicating that compliment pragmatics not only varies across different cultures, but also across different dialects of the same language. Such cross-cultural and cross-dialectal variations are very important information for people to learn to avoid mis-understandings in inter- and intra-cultural communications.

${ }^{7}$ This traditional view of valuing fuller figures is undergoing changes among the younger generations in China under the influence of western cultures. 


\section{Closing Remarks}

The present article gives an overview of compliments and compliment responses in Kunming Chinese produced in both natural settings and DCT questionnaires. Data are analysed in great detail both quantitatively and qualitatively and the three research questions are answered adequately. We believe that the findings presented in this article can provide a good understanding of the speech event in the dialect. They also highlight some similarities and differences of complimenting behaviour between Kunming Chinese and other languages/dialects and the need to use different types of datagathering methods to provide a complete picture of the language phenomenon under study.

\section{References}

Beebe, Leslie M. (1994) Notebook data on power and the power of notebook data. Paper presented at TESOL '94 Conference in Baltimore, USA.

Beebe, L. M., \& Cummings, M. C. (1996) Natural speech act data versus written questionnaire data: How data collection method affects speech act performance. In S. M. Gass and J. Neu (eds.), Speech acts across cultures: Challenges to communication in a second language. Berlin: Mouton de Gruyter, 65-86.

Blum-Kulka, S. \& Olshtain, E. (1984) Requests and apologies: A cross-cultural study of speech act realisation patterns (CCSARP). Applied Linguistics 5: 196-213.

Brown, P. \& Levinson, S. (1987) Politeness: Some universals in language usage. Cambridge, MA: Cambridge University Press.

Chan, Po Hui (1981) Modern Chinese dialects. Wuhan: Hubei People's Publishing House.

Chen, Rong (1993) Responding to compliments: A contrastive study of politeness strategies between American English and Chinese speakers. Journal of Pragmatics, 20: 49-75.

Chen, X., Ye, L., \& Zhang, Y.Y. (1995) Refusing in Chinese. In G. Kasper (ed.), Pragmatics of Chinese as native and target language. Honolulu: Second Language Teaching \& Curriculum Centre, University of Hawaii at Manoa, 119-164.

Cordella, M., Large, H., \& Pardo, V. (1995) Complimenting behaviour in Australian English and Spanish speech. Multilingua 143: 235-252.

Daikuhara, Midori (1986) A study of compliments from a cross-cultural perspective: Japanese vs. American English. Penn Working Papers in Educational Linguistics 2(2): 23-41.

Edmundson, Robin J. (1992) Evidence for native speaker notions of apologising and accepting apologies in American English. Unpublished Ph.D. Dissertation, Indiana University, Bloomington. 
Gui, Ming Chao (1990) Yunnanese and Kunming Chinese: A study of the language communities, the phonological systems, and the phonological developments. Unpublished Ph.D. Dissertation, The University of Texas, Arlington.

Hartford, Beverly S. (1994) Complaints in Nepali English. Paper presented at the International English Language Education Conference, Kuala Lumpur.

Hartford, B. S., \& Bardovi-Harlig, K. (1992) Experimental and observational data in the study of interlanguage pragmatics. In: L. Bouton and Y. Kachru (eds.), Pragmatics and language learning, monograph 3. Urbana, Illinois: DEIL, 33-50.

Herbert, Robert (1986) Say "Thank you" - Or something. American Speech 61(1): 76-88.

Herbert, Robert (1990) Sex-based differences in compliment behaviour. Language in Society 19: 201224.

Herbert, Robert (1991) The sociology of compliment work: An ethnocontrastive study of Polish and English compliments. Multilingua 10(4): 381-402.

Herbert, R, \& Straight, S. (1989) Compliment-rejection versus compliment-avoidance: Listener-based versus speaker-based pragmatic strategies. Language and Communication, 9(1): 35-47.

Holmes, Janet (1988a) Compliments and compliment responses in New Zealand English. Anthropological Linguistics 28: 485-508.

Holmes, Janet (1988b) Paying compliments: A sex-preferential positive politeness strategy. Journal of Pragmatics 12: 445-465.

Holmes, Janet (1990) Apologies in New Zealand English. Language in Society 19(2): 155-199.

Jaworski, Adam (1995) "This is not an empty compliment!": Polish compliments and the expression of solidarity. International Journal of Applied Linguistics 5(1): 63-94.

Johnson, D.M., \& Roen, D.H. (1992) Complimenting and involvement in peer reviews: Gender variation. Language in Society 21: 27-57.

Knapp, M. L., Hopper, R., \& Bell, R.A. (1984) Compliments: A descriptive taxonomy. Journal of Communication 34(4): 12-31.

Lee, Candis (1990) Cute yaw haiya-nah! Hawai'i Creole English compliments and their responses: Implications for cross-cultural pragmatic failure. University of Hawai'i Working Paper in ESL 9(1): 115161.

Lewandowska-Tomaszczyk, Barbara (1989) Praising and complimenting. In W. Oleksy (ed.), Contrastive pragmatics. Amsterdam: Benjamin's, 73-100.

Manes, Joan (1983) Compliments: A mirror of cultural values. In N. Wolfson and E. Judd (eds.), Sociolinguistics and language acquisition. Rowley, Mass.: Newbury House, 96-102.

Manes, J., \& Wolfson, N. (1980) The compliment formula. In F. Coulmas (ed.), Conversational routine. The Hague: Mouton, 115-132.

Milroy, Leslie (1980) Language and social networks. Oxford: Blackwell. 
Nelson, G.L., Bakary, W. E., \& Al-Batal, M. (1993) Egyptian and American compliments: A crosscultural study. International Journal of Intercultural Relations 17: 293-313.

Norman, Jerry (1988) Chinese. Cambridge: Cambridge University Press.

Pomerantz, Anita (1978) Compliment response: Notes on the cooperation of multiple constraints. In J. Schenkein (ed.), Studies in the organisation of conversational interaction. New York: Academic Press, 79-112.

Rose, K.R., \& Ono, R. (1995) Eliciting speech act data in Japanese: The effect of questionnaire type. Language Learning 45(2): 191-223.

The New English-Chinese Dictionary Editorial Team (1979) A new English-Chinese dictionary. Shanghai: Shanghai Translated Works Press.

Wieland, Molly (1995) Complimenting behaviour in French/American cross-cultural dinner conversations. The French Review, 68(5): 796-812.

Wolfson, Nessa (1981) Compliments in cross-cultural perspective. TESOL Quarterly 15(2): 117-124.

Wolfson, Nessa (1983) An empirically based analysis of complimenting in American English. In N. Wolfson and E. Judd (eds.), Sociolinguistics and language acquisition. Rowley, MA: Newbury House, 82-95.

Wolfson, Nessa (1984) Pretty is as pretty does: A speech act view of sex roles. Applied Linguistics 5: 236-244.

Wolfson, Nessa (1989) The social dynamics of native and nonnative variation in complimenting behaviour. In M. Eisenstein (ed.), The dynamic interlanguage: Empirical studies in second language variation. New York: Plenum, 219-236.

Wolfson, N., \& Manes, J. (1980) The compliment as a social strategy. Papers in Linguistics 13(3): 391410.

Ye, Lei (1995) Complimenting in Mandarin Chinese. In G. Kasper (ed.), Pragmatics of Chinese as native and target language. Honolulu: Second Language Teaching \& Curriculum Centre, University of Hawai'i at Manoa, 207-302.

Yuan, Yi (2000) Sociolinguistic variations of the compliment event in Kunming Chinese. Paper presented at the $29^{\text {th }}$ Annual Conference on New Ways of Analysing Language Variation (NWAV). Michigan State University, USA, October 5-8, 2000.

Yuan, Yi (2001) An inquiry into empirical pragmatics data-gathering methods: Written DCTs, oral DCTs, field notes, and natural conversations. Journal of Pragmatics 33(2): 271-292.

Zhang, Yan Yin. (1995) Strategies in Chinese requesting. In G. Kasper (ed.), Pragmatics of Chinese as native and target language. Honolulu: Second Language Teaching \& Curriculum Centre, University of Hawaii at Manoa, 23-68. 


\section{Appendix I. The Topics of the DCT Questionnaire}

\begin{tabular}{|c|c|c|c|}
\hline \multicolumn{4}{|c|}{ COMPLIMENTS } \\
\hline Topic & Gender of Complimentee & Situation & Object of Compliment \\
\hline (1) $\overline{\text { Child }}$ & Male & $\mathrm{S} 1$ & bright child \\
\hline Child & Female & S3 & obedient daughter \\
\hline (2) Ability & Female & $\mathrm{S} 2$ & Ph.D. \\
\hline Ability & Male & S4 & computer \\
\hline (3) Appearance & Male & S5 & age (looking young) \\
\hline Appearance & Female & S7 & new hair cut \\
\hline (4) Attire & Male & S6 & new leather jacket \\
\hline Attire & Female & S8 & new dress \\
\hline (5) Possession & Male & S9 & new carpet \\
\hline Possession & Female & S11 & newly renovated house \\
\hline (6) Whole Person & Female & $\mathrm{S} 10$ & thoughtfulness \\
\hline Whole Person & Male & $\mathrm{S} 12$ & kindness \\
\hline \multicolumn{4}{|c|}{ RESPONSES } \\
\hline Topic & Gender of Complimenter & Situation & Object of Compliment \\
\hline (1) $\overline{\text { Child }}$ & Male & $\mathrm{S} 16$ & good logic thinking \\
\hline Child & Female & S20 & chess champion \\
\hline (2) Ability & Male & $\mathrm{S} 15$ & speech competition \\
\hline Ability & Female & $\mathrm{S} 19$ & supporting family \\
\hline (3) Appearance & Female & S18 & age (looking young) \\
\hline Appearance & Male & S24 & look (putting on weight) \\
\hline (4) Attire & Male & $\mathrm{S} 14$ & dressing up \\
\hline Attire & Female & $\mathrm{S} 17$ & new dress at wedding \\
\hline (5) Possession & Female & S21 & clean, nice house \\
\hline Possession & Male & S23 & new colour TV \\
\hline (6) Whole Person & Female & $\mathrm{S} 13$ & kindness \\
\hline Whole Person & Male & $\mathrm{S} 22$ & generosity \\
\hline
\end{tabular}

\section{Appendix II. The English Translation of the Chinese Questionnaire}

Instructions: The following is a questionnaire about the use of Kunming Chinese. Please provide as much information as possible based on your experience in everyday life. Imagine yourself in the situations given and write in the space provided what exactly you would say in real life. If for some reason you think you will not say anything in a particular situation, note that in the same space. Please fill out the questionnaire in order.

\section{Part One}

1. When you drop by your friend Zhang Yong-gang's place, you see his four-year-old son working on second grade math problems with great interest. You say to Zhang Yong-gang: 
This space will be omitted in the following scenarios.

2. Zhu Yan, an acquaintance, got her Ph.D. from Beijing University before she turned thirty and then found a very good job. When you saw her yesterday, you talked about this. You said to her with admiration:

3. The four-year-old daughter of your neighbour is a very good girl. One day you went to their house with your own daughter. At 8:30 p.m., your neighbour said to her daughter, "Ling Ling, it's time for bed." Ling Ling said, "OK", and retreated to her room. You say to her mother:

4. Your friend Li Gang-qiang is very good both at work and at home. After he successfully fixes a computer for a friend today, you say to him:

5. You are going to meet somebody called Wang Jian-guo at the airport today. You've never met him before, but from the name you guess he must be $46-47$ years old. When you see him, you find he is still in his twenties. You say to him:

6. You see your elder brother wearing a new leather jacket today. He looks really good. You say to him:

7. Your friend Su Ling-ling had her hair cut short yesterday. She looks very energetic and cute. When you see her today, you say to her:

8. Your colleague Li Xiu-mei is wearing a pretty, fashionable dress from Hong Kong today. You see it and say to her:

9. When you visited your neighbour Xu Tao recently, you found that he had just bought a very nice blue carpet. You said to him:

10. Your friend Lo Xia is a very nice person, who always places other people's interest before her own. One day you said to her with admiration:

11. You go to see the newly remodelled house of your friend Yang Li-hua and find it very artistic and comfortable. You say to her:

12. Zhao Nan is an acquaintance of yours. He is very honest and loves to help others. Lately a friend of his was hospitalised. Zhao Nan not only gave him blood, but also went to see him everyday. You heard about this and said to him with admiration: 
13. Your son has a little friend $\mathrm{Da} \mathrm{Li}$, who frequently comes to play in your house. You often play with them for hours. Da Li's mother is very grateful for this. Today Da Li comes again. When his mother comes to pick him up, she says to you, "Oh, thank you so much. Da Li keeps telling me you're the nicest person in the world." You say to her:

14. It's Saturday today. You and your family plan to go to the Green Lake Park to take pictures. You are all dressed up. At the door, you meet your neighbour Li Jing. $\mathrm{He}$ says, "Wow, you're all dressed up so beautifully today!" You say to him:

15. Not long ago you got to know somebody called Lei Peng on a train to Beijing. In your conversation with him, you mentioned that you had just been to Hong Kong to compete in the International Speech Competition for Yunnan Province. He was really impressed and said with admiration, "Wow, you were in the provincial team! You're really good." You said to him:

16. When you and your neighbour Zhao Da-hai both took kids to school the other day, Zhao Da-hai said to you on the way, "your son Xiao Bo is very bright. He's especially good at logical thinking. He'll definitely have a great future." You replied:

17. You went to a wedding yesterday, wearing a newly-bought, expensive clothes. The bride loved your outfit and said to you in compliment, "Wow, you're dressed up so beautifully!" You said:

18. You've been relaxing all the summer and are feeling really good. Your neighbour Zhao Lan saw you at the door this morning and said: "You look so young today! I saw someone at a distance, and was wondering who it was. So young!" You said to her:

19. You're the oldest child in the family and began to look after your younger brothers and sisters at an early age for your parents. Now as a grown-up, you're supporting the whole family. Your neighbour Jiang Hong knows about this and said to you one day, "Oh, you're really a capable person. I wouldn't know what to do if I were you." You said to her:

20. Your five-year-old daughter is an excellent chess-player. She won the championship yesterday in the Provincial Children's Chess Competition. Your friend Xiao Mei saw you today and said to you, "Your daughter Xiao Ping is so good. She plays chess so well!" You replied:

21. You always keep your house clean and tidy. One day your friend Li Li dropped by and was very much impressed. She said, "Your place is always so nice and clean!" You said to her: 
22. You're always generous and willing to help other people. One day, your colleague Li Chuan said to you, "You're really nice and kind. I admire and respect you very much." You said to him:

23. You just bought a 29' imported colour TV the other day. Li Ming, an acquaintance, saw it and said to you, "Have you just bought this new TV? It's beautiful." You said to him:

24. You went to Shanghai for job training for six months. When you came home, your big brother said to you: "You seem to have gained a little weight. You look really nice." You said to him:

\section{Note}

1. This name implies that the person (most likely a man) bearing the name was born at the time when China was founded, namely, in 1949. That means he was around the age of 46 or 47 when the questionnaire was administered. 